Portland State University

PDXScholar

\title{
The Nature of Kinematic Waves in Glaciers and their Application to Understanding the Nisqually Glacier, Mt. Rainier, Washington
}

Brita llyse Horlings

Portland State University

Follow this and additional works at: https://pdxscholar.library.pdx.edu/honorstheses

Let us know how access to this document benefits you.

\section{Recommended Citation}

Horlings, Brita llyse, "The Nature of Kinematic Waves in Glaciers and their Application to Understanding the Nisqually Glacier, Mt. Rainier, Washington" (2016). University Honors Theses. Paper 248.

https://doi.org/10.15760/honors.308

This Thesis is brought to you for free and open access. It has been accepted for inclusion in University Honors Theses by an authorized administrator of PDXScholar. Please contact us if we can make this document more accessible: pdxscholar@pdx.edu. 
The Nature of Kinematic Waves in Glaciers and Their Application to Understanding the Nisqually Glacier, Mt. Rainier, Washington

by

Brita Ilyse Horlings

An undergraduate honors thesis submitted for partial fulfillment of the requirements for the degree of

Bachelor of Science

in

University Honors

and

Geology

Primary Thesis Adviser

Andrew G. Fountain

Secondary Thesis Adviser

Maxwell L. Rudolph

Portland State University

2016 


\begin{abstract}
The Nisqually Glacier is one of the best studied glaciers on Mt. Rainier. Data was first collected on the glacier in 1857 and since then a number of kinematic waves have been observed but not extensively studied. The purpose of the thesis is to numerically model the conditions that favor or restrict kinematic wave propagation/initiation and subsequently model the relationship between kinematic wave behavior and the Nisqually Glacier. The numerical models used in this study are 2-D and use bedrock elevation, mass balance, basal sliding, and other equations to simulate alpine glaciers. A perturbation is added instantaneously for a specified time interval to the mass balance of the model glacier to allow for possible kinematic wave formation, and parameters such as ice velocity, ice thickness changes, and time elapsed are subsequently recorded. Through the use of the model, the principal research findings include 1) both magnitude and duration of a mass balance perturbation affect kinematic wave behavior, 2) glaciers on steeper slopes show a greater response to small mass balance perturbations of $\sim 0.5 \mathrm{~m}$. w.e. for 1 year compared to glaciers on less steep slopes, 3) a $6 \mathrm{~m}$. w.e. perturbation for 3 years creates a Nisqually Glacier response similar to those seen from its historical waves, suggesting that there are other factors contributing to kinematic wave formation, and 4) the Nisqually Glacier has prominent advances with all mass balance perturbations, leading to the conclusion that even small increases in the mass balance can show significant length change.
\end{abstract}




\section{Table of Contents}

$\begin{array}{ll}\text { List of Tables } & 5\end{array}$

$\begin{array}{lr}\text { List of Figures } & 6\end{array}$

$\begin{array}{ll}\text { 1. Problem Statement } & 7\end{array}$

$\begin{array}{ll}\text { 2. Introduction } & 7\end{array}$

2.1 Glaciers and Climate $\quad 7$

2.2 Kinematic Waves $\quad 8$

2.3 Study Site: Nisqually Glacier, Mt. Rainier

3. Model Description 13

3.1 Domain 14

3.2 Mass Balance $\quad 15$

3.3 Bed Topography 19

3.4 Flow law, Momentum Balance, and Continuity Equations 22

$\begin{array}{ll}3.5 \text { Basal Sliding } & 24\end{array}$

$\begin{array}{ll}3.6 & \text { Temperature profile }\end{array}$

3.7 Geothermal and Isostatic Responses

4. Model Kinematic Wave Formation 25

4.1 Altering the Mass Balance 26

4.2 Altering Slope Steepness 27

5. Model Results for Theoretical Glacier 28 
7. Conclusion

8. References 


\section{List of Tables}

Table 1. The 11 data points taken from Figure $5 b$ of Meier and Tangborn (1965)....................15

Table 2. The transformation of Profiles 1, 2, and 3 from the 1976 glacier to the present-day

glacier.

Table 3. Results from the Nisqually glacier model trials for the elevation change of Profiles 1, 2, and

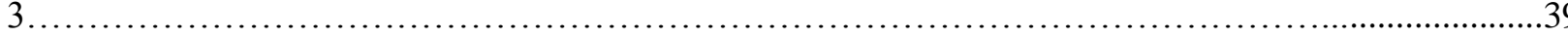

Table 4. The approximate arrival times (in model years) for the Nisqually Glacier experiments. Note that the mass balance perturbation begins at year 5 and ends either at year 6 or year 8 for the various

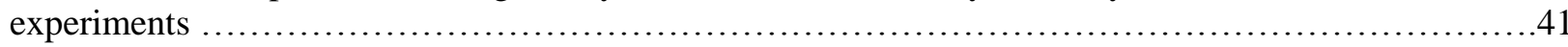

Table 5 Approximate wave speeds for each Nisqually Glacier model experiment. 


\section{List of Figures}

Figure 1. The glaciers of Mt. Rainier, Washington on a LiDAR image (USGS, 2012).................10

Figure 2. The Nisqually Glacier, on the southern side of Mt. Rainier (Veatch, 1969)..................11

Figure 3. Transect 1, 2, and 3 (profiles 1, 2, and 3) from Heliker (1984) shown on a 2011 LiDAR derived

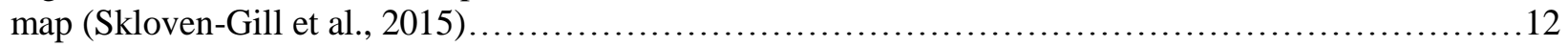

Figure 4. Experiments with nodal spacings of $50 \mathrm{~m}, 10 \mathrm{~m}$, and $5 \mathrm{~m}$ (left to right). Note that all nodal spacing experiments used $1 \mathrm{~m}$. w.e. perturbation for 3 years..................................... 15

Figure 5. a) Mass balance curve approximated by the 10th degree Langrange interpolating polynomial. b) Figure 5b of Meier and Tangborn (1965) showing the South Cascade mass balance curve................16

Figure 6. The mass balance curve used for the theoretical model glacier...........................17

Figure 7. The linear mass balance function used for the Nisqually Glacier model.........................18

Figure 8. From Allstadt et al (2015), figure 6. (a) and (c): Slope parallel velocity profiles for the West and East Profile of the Nisqually Glacier, (b) and (d): surface slope and ice thickness for the West and East Profile. Surface slope is smoothed identically to that used for slope parallel corrections (see text), ice thicknesses are estimated from digitized basal contours from Driedger and Kennard (1986) and surface

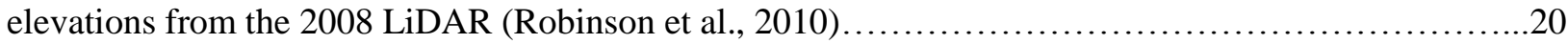

Figure 9. A plot showing the Nisqually Glacier model using the West Profile bed topography.................21

Figure 10. The uniform and instantaneous mass balance perturbation used to initiate kinematic wave formation. This is an example of a $1 \mathrm{~m}$. w.e. perturbation lasting for 3 years........................27

Figure 11. The mass balance perturbation as a kinematic wave (a). The terminus change is the most prominent. The form is similar to that found by Van de Waal and Oerlemans (1995 (b)).......................29

Figure 12. Surface elevation and change in ice thickness for different mass balance perturbations

Figure 13. The change in ice thickness through time at $2.15 \mathrm{~km}$, the ELA, $5.10 \mathrm{~km}$ down from the head of the glacier, and just beyond the terminus of the time=0yrs glacier..................................

Figure 14. Experiments using $0.5 \mathrm{~m}$. w.e. perturbation for 1 years and $1 \mathrm{~m}$. w.e. perturbation for 3 years

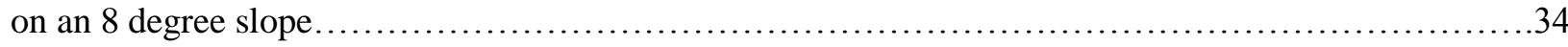

Figure 15. Mass balance perturbations for $0.5 \mathrm{~m}$. w.e. for 1 year and 3 years and $1 \mathrm{~m}$. w.e. for 1 year and 3 years. Profiles 1, 2, and 3 are the successively upglacier red stars (respectively)..................................37

Figure 16. Mass balance perturbation of 2 m. w.e., 4 m.w.e., and 6 m.w.e. for 3 years......................38

Figure 17. Ice elevation change of Profiles 1, 2, and 3 through time for two experiments: $0.5 \mathrm{~m}$. w.e. for 1

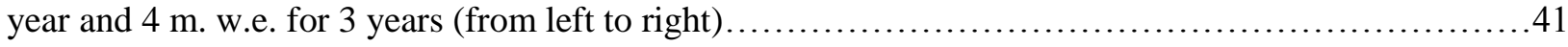

Figure 18. The terminus behavior for three Nisqually Glacier model experiments. From left to right and top to bottom: maximum advance for $0.5 \mathrm{~m}$. w.e. perturbation for 1 year, maximum advance for 2 m.w.e.

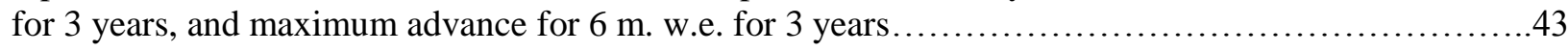




\section{Problem Statement}

Are there conditions that restrict or favor the initiation and propagation of kinematic waves on a glacier? From this analysis, what can be learned about the kinematic wave behavior of the Nisqually Glacier?

\section{Introduction}

In this thesis I examine the behavior of kinematic waves in order to analyze a glacier's response to climatic variations. Firstly, I investigate controlling factors for the initiation and propagation of kinematic waves on glaciers by using a theoretical numerical model. Secondly, I apply the understanding of kinematic waves to the Nisqually Glacier on Mt. Rainier, Washington. I will use data to construct a numerical model that simulates the Nisqually Glacier. These results will better our understanding of a glacier's response to climatic variations and also to help decipher confounding observations, such as glacier advance and thickening, for the present climatic conditions.

\subsection{Glaciers and Climate}

Glaciers are sensitive indicators of variations in climate (Nye, 1960). Climate variations change a glacier's mass balance by affecting ablation and accumulation amounts. A small ablation increase may cause substantial mass loss from a glacier (Van de Waal and Oerlemans, 1960). A small change in accumulation may also cause a great response such as glacier thickening and advance (Nye, 1960). Mass instabilities, such as kinematic waves, are critical research areas for examining glacier response due to climatic variations. In particular, kinematic 
waves may be a temporary confounding factor in the assessment of glacier retreat instigated by global warming. This is because kinematic waves produce responses such as glacier thickening and advance that are not generally expected in today's current climate situation.

\subsection{Kinematic Waves}

Kinematic waves on glaciers are mass instabilities that occur to restore equilibrium from a sudden accumulation of mass (Nye, 1960). Kinematic waves form as a result of mass conservation, and more specifically, a result of a fixed ice flux (Hooke, 2005). Kinematic waves are common to all fluid flows and are not restricted to glaciers (Lighthill and Whitham, 1955). Unlike dynamic waves such as water waves, kinematic waves do not arise from inertial forces (Hooke, 2005). On glaciers, this is because inertial forces are minimal due to their low velocities and high viscosities (Hooke, 2005). The formation and propagation of kinematic waves involves three stages: 1) when ice flux into a specified glacier length section is greater than the flux out of it, thickening occurs; 2) this results in a greater ice flux and velocity in the thicker section than the surrounding thinner sections; 3 ) a kinematic wave forms and travels down-glacier at higher velocities than the surrounding ice (Hooke, 2005).

Kinematic wave behavior is highly dependent on location along the glacier. From their Hintereisferner experiment, Van de Waal and Oerlemans (1995) concluded that velocity increases only slightly in the accumulation zone because of the effect of an increase in ice thickness and reduced surface slope. However, even small changes in ice thickness and surface slope have appreciable increases in velocity (usually 10\%) in the ablation zone (Van de Waal 
and Oerlemans, 1995). This can amount to a kinematic wave velocity of 2-5 times the ice surface velocity (Nye, 1960).

All sections of the glacier thicken during a uniform increase in mass balance (Nye, 1960). However, the change in ice thickness depends on the sensitivity of that particular part of the glacier. At the terminus and up into the ablation zone, the glacier thickens unstably (Nye, 1960). This thickening and any advance of the glacier can be substantial even for small mass balance increases (Nye, 1960). The glacier restores equilibrium from the head of the glacier to the terminus (Van de Waal and Oerlemans, 1995). In Van de Waal and Oerleman's Hintereisferner exmperiment, equilibrium was restored after about 70 years for a wave amplitude of $5 \mathrm{~m}$ (1995).

Observations of kinematic waves have been limited because they are difficult to detect in the field. Kinematic wave velocities are generally not greater than $10 \%$ of the surrounding ice (Van der Wal and Oerlemans, 1995). This low percentage makes it difficult to accurately record kinematic wave propagation. In addition, field identification is difficult because of responses such as quick diffusion of the wave (Van der Wal and Oerlemans, 1995).

\subsection{Study Site: Nisqually Glacier, Mt. Rainier}

The Nisqually Glacier is located on the southern slope of Mt. Rainier, Washington (figure 1 and 2) (Veatch, 1969). It is approximately $6.4 \mathrm{~km}$ in length (Allstadt et al, 2015, and Hodge, 1972) with an elevation of approximately $4360 \mathrm{~m}$ at the head (Allstadt et al., 2015). The Nisqually Glacier is one of the best studied glaciers on Mt. Rainier. Terminus position and advances/retreats have been measured continuously since the early 1900s (Heliker, 1984). In addition, a 24-year photographic record details the Nisqually Glacier's change from 1941-1965 (Veatch, 1969). 


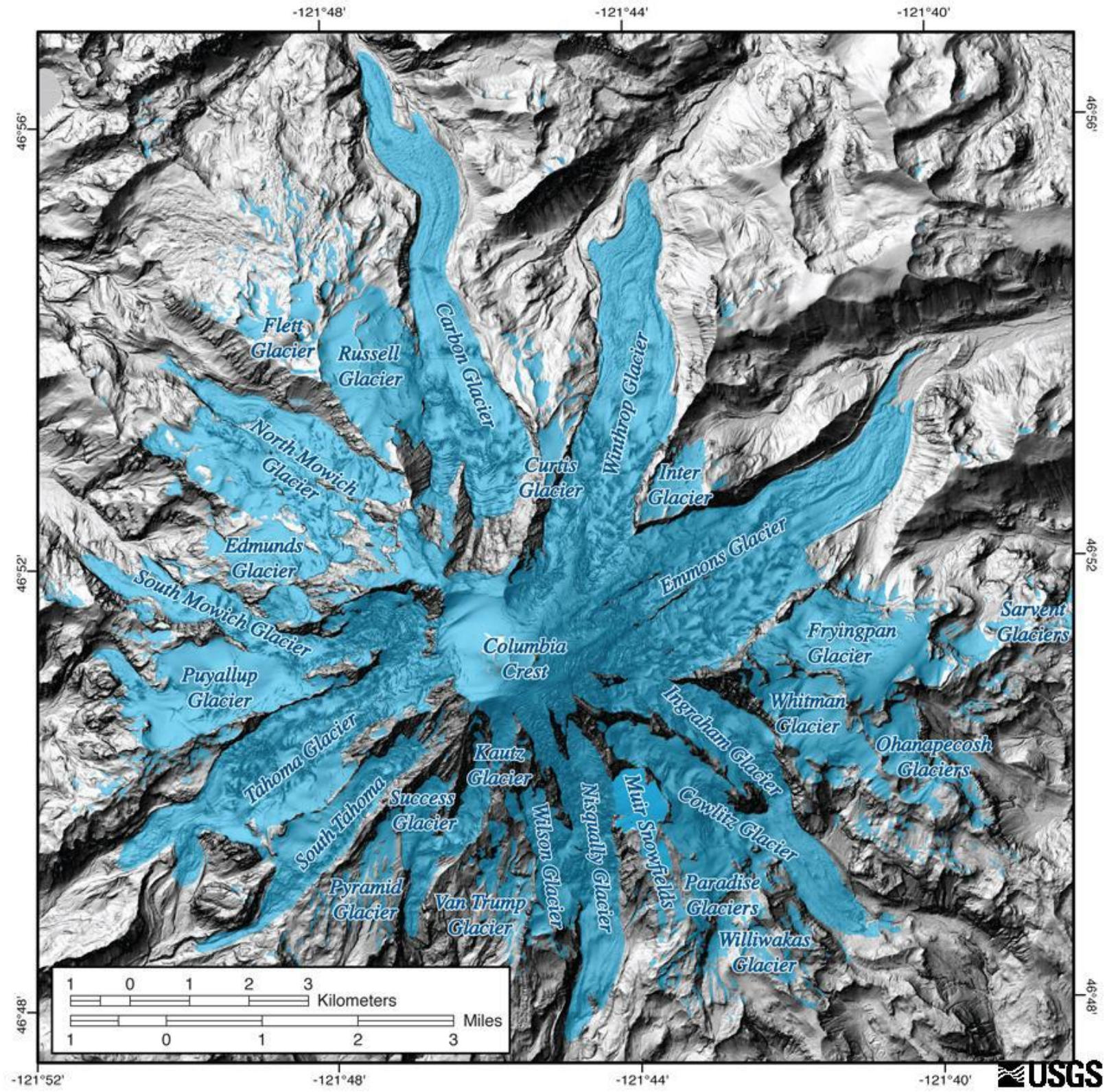

Figure 1. The glaciers of Mt. Rainier, Washington on a LiDAR image (USGS, 2012). 


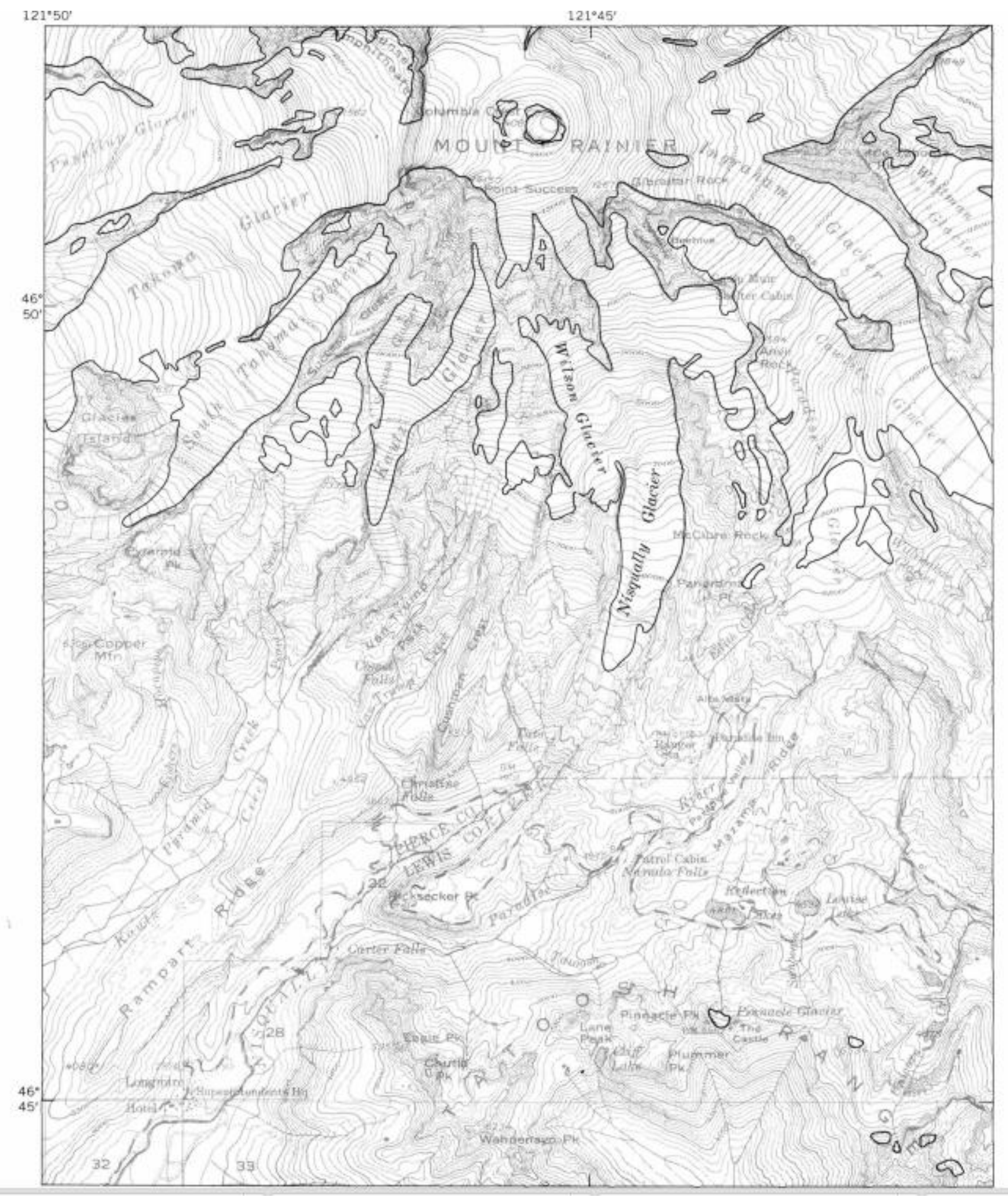

Figure 2. The Nisqually Glacier is on the southern slope of Mt. Rainier (Veatch, 1969). 
The Nisqually Glacier has been monitored for advance and retreat since the first recorded observation of the terminus in 1857 (Heliker et al., 1984). There were prominent recessions from 1857 to 1963,1969 to 1975 (Heliker et al., 1984), and 1986 to 2001, advances from 1964 to 1969 and 1976 to 1982, and periods of no change from 1983 to 1986 (Krimmel, 2002). Smaller changes have also been recorded, such as the small advance of 1905 to 1908 (Heliker et al., 1984). Between 1857 and 2002, the Nisqually Glacier had advanced a total of $294 \mathrm{~m}$ and receded a total of $1945 \mathrm{~m}$ (Krimmel, 2002). However, the presence of a stagnant debris-covered terminus from 1951 to 1964 may have led to incorrect conclusions about terminus behavior during this time (Heliker et al., 1984).

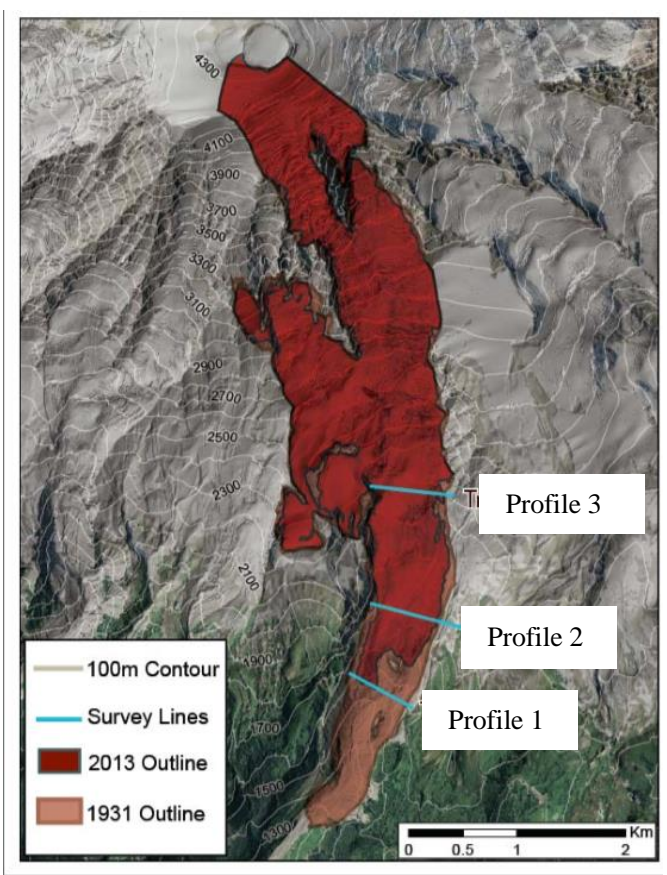

Figure 3. Transect 1, 2, and 3 (profiles 1, 2, and 3) from Heliker et al. (1984) shown on a 2011 LiDAR derived map (Skloven-Gill and Fountain, 2015). 
Ice-surface altitude profiling from 1941-1976 recorded several kinematic waves on the Nisqually Glacier (Heliker et al., 1984). Three profiles were surveyed using transit and stadia rods (Heliker et al., 1984). In particular, profiles 1, 2, and 3 were measured 550m, 1,300m, and 2,370m up-glacier of the 1976 terminus (figure 3) (Heliker et al., 1984). The largest and first recorded wave passed the uppermost profile (profile 3) in 1944 (Heliker et al., 1984) and had a maximum mean altitude measurement of $31 \mathrm{~m}$ at profile 2 (Heliker et al., 1984). This same wave reached the terminus in 1964 (Heliker et al., 1984). A smaller wave was recorded to have passed profile 3 in 1956, profile 2 in 1963, and profile 1 in 1965 (Heliker et al., 1984).

\section{Model description}

Two variations of a 2-D numerical models are used in this study: one simulating a flatbedded alpine glacier and the other simulating the Nisqually Glacier. Both numerical models were modified from the PSU/UofC flowline model for ice-sheet evolution (Parizek et al., 2005). The model uses the Galerkin method of weighted residuals, which is a finite-element modeling (FEM) technique (Parizek et al., 2005). In addition, the model uses both linear and Hermitian polynomial based functions for thermal and dynamic calculations (Parizek et al., 2005). The model is constructed so that $\mathrm{x}$ coordinates relate to locations along the flowline of the glacier and y coordinates relate to elevations (Parizk et al., 2005). A detailed description of the PSU/UofC flowline model is presented in Parizek et al. (2005). However, I significantly modified the PSU/UofC flowline model to produce the two variations I use in my thesis. 


\subsection{Domain}

The model is divided into a grid $10 \mathrm{~km}$ long with $10 \mathrm{~m}$ nodal spacings. There are several experiments that are developed with different nodal spacings $(50 \mathrm{~m}, 10 \mathrm{~m}$, and $5 \mathrm{~m})$ in order to find stable glacier behavior. The approximation of the solution is affected by nodal spacing (figure 4). For example, a $50 \mathrm{~m}$ nodal spacing restricts glacier behavior. The advance of the terminus can only occur when the glacier has to advance $50 \mathrm{~m}$. No smaller advance (or retreat) is permitted, hence the uneven terminus curve. However, the $10 \mathrm{~m}$ nodal spacing is less restricted and the glacier's advance and retreat appears more natural and less constrained compared to the $50 \mathrm{~m}$ nodal spacing. The $5 \mathrm{~m}$ nodal spacing shows similar glacier behavior as the $10 \mathrm{~m}$ nodal spacing, allowing almost unhindered glacier advance or retreat. The time step is dependent on nodal spacing of the model. Generally, smaller nodal spacings need smaller time steps. For example, with the theoretical model of $10 \mathrm{~m}$ and $5 \mathrm{~m}$ nodal spacings, a time step of 1/300 yrs. and 1/1000 yrs. respectively is necessary to obtain convergence to a solution.

A balance between accuracy and efficiency is integral in assigning a nodal spacing for the model. The model should produce results that approximate the glacier's response accurately, yet should run at a practical speed to ensure an adequate progression of results. Because both a $10 \mathrm{~m}$ nodal spacing and a $5 \mathrm{~m}$ nodal spacing indicate similar glacier behavior, the $10 \mathrm{~m}$ nodal spacing can be chosen for use. 

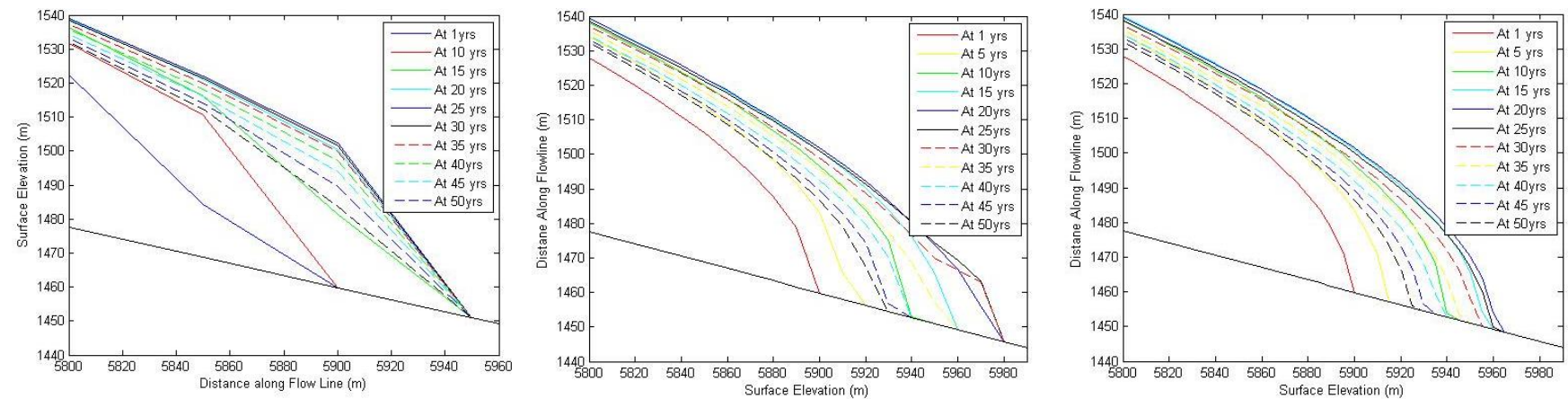

Figure 4. Experiments with nodal spacings of 50m, 10m, and $5 \mathrm{~m}$ (left to right). Note that all nodal spacing experiments used $1 \mathrm{~m}$. w.e. perturbation for 3 years.

\subsection{Mass Balance}

The theoretical model uses a mass balance that is derived from the South Cascade mass balance curve described in Meier and Tangborn (1965). Eleven data points, shown in table 1, are acquired from figure 5b of Meier and Tangborn (1965). Data points are taken with closer elevation increments near the end points of the data set to ensure the accuracy at the bounds.

Table 1. The 11 data points taken from Figure 5b of Meier and Tangborn (1965).

\begin{tabular}{cc}
\hline$z_{i}($ Elevation $(m))$ & $f\left(z_{i}\right)$ (Mass Balance $(m$ w.e. $)$ \\
\hline \hline 1400 & -9.30 \\
1450 & -8.30 \\
1500 & -7.30 \\
1600 & -5.30 \\
1700 & -3.22 \\
1800 & -1.27 \\
1900 & 0.62 \\
2000 & 1.37 \\
2040 & 1.40 \\
2100 & 0.90 \\
2140 & 0.60 \\
\hline
\end{tabular}


A $10^{\text {th }}$ degree Lagrange interpolating polynomial is used to approximate a mass balance curve (equation 1). Note that $f\left(z_{0}\right) . f\left(z_{i}\right)$ is net mass balance and $z_{0} \ldots z_{i}$ is elevation where $i=10$.

$$
\begin{gathered}
P_{10}(x)=f\left(z_{0}\right) * \frac{\left(z-z_{1}\right)\left(z-z_{2}\right)\left(z-z_{3}\right)\left(z-z_{4}\right)\left(z-z_{5}\right) \ldots\left(z-z_{10}\right)}{\left(z_{0}-z_{1}\right)\left(z_{0}-z_{2}\right)\left(z_{0}-z_{3}\right)\left(z_{0}-z_{4}\right)\left(z_{0}-z_{5}\right) \ldots\left(z_{0}-z_{10}\right)}+\ldots \\
\ldots f\left(z_{1}\right) * \frac{\left(z-z_{0}\right)\left(z-z_{2}\right)\left(z-z_{3}\right)\left(z-z_{4}\right)\left(z-z_{5}\right) \ldots\left(z-z_{10}\right)}{\left(z_{1}-z_{0}\right)\left(z_{1}-z_{2}\right)\left(z_{1}-z_{3}\right)\left(z_{1}-z_{4}\right)\left(z_{1}-z_{5}\right) \ldots\left(z_{1}-z_{10}\right)}+\ldots \\
\ldots f\left(z_{11}\right) * \frac{\left(z-z_{0}\right)\left(z-z_{2}\right)\left(z-z_{3}\right)\left(z-z_{4}\right)\left(z-z_{5}\right) \ldots\left(z-z_{10}\right)}{\left(z_{10}-z_{0}\right)\left(z_{10}-z_{2}\right)\left(z_{10}-z_{3}\right)\left(z_{10}-z_{4}\right)\left(z_{10}-z_{5}\right) \ldots\left(z_{10}-z_{9}\right)}
\end{gathered}
$$

The resulting mass balance function is displayed in figure 5a. This matches the general shape of Meier and Tangborn's (1965) South Cascade mass balance curve (figure 5b). Note that the unevenness of their curve is eliminated because only 11 data points are used.
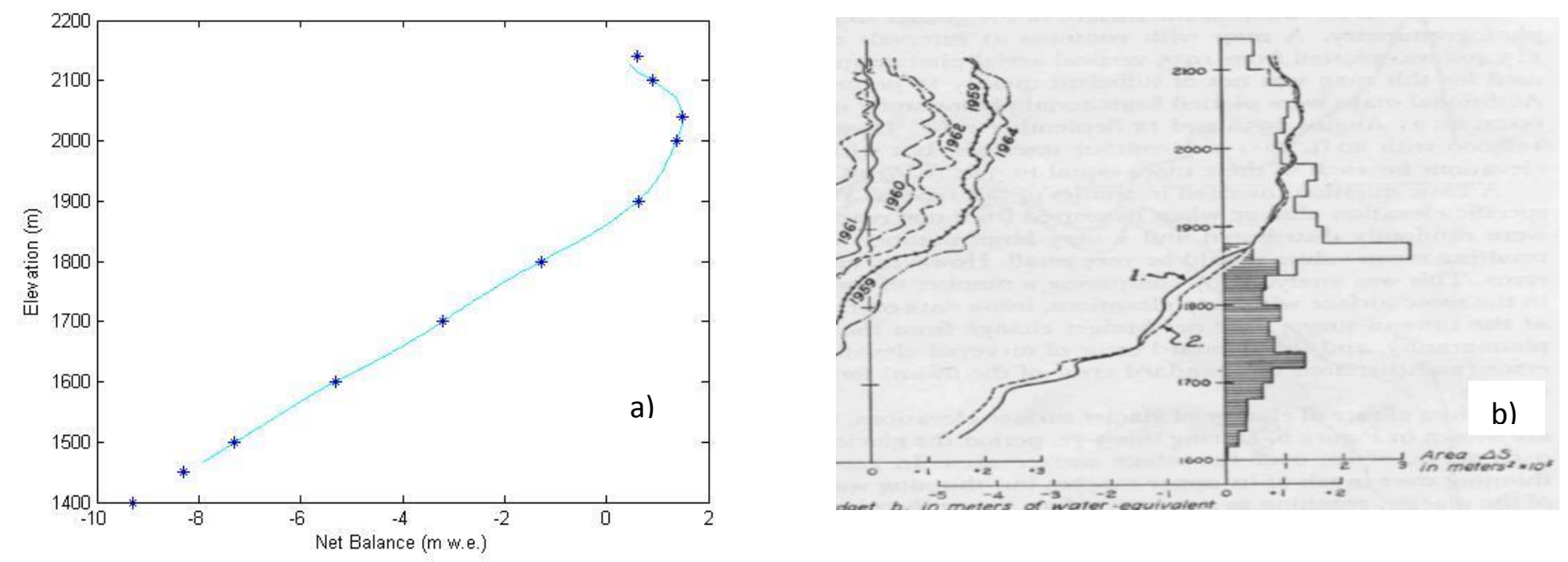

Figure 5. a) Mass balance curve approximated by the $10^{\text {th }}$ degree Langrange interpolating polynomial. b) Figure 5b of Meier and Tangborn (1965) showing the South Cascade mass balance curve. 
The mass balance curve is extrapolated below $1450 \mathrm{~m}$ elevation with a linear function. A constant net mass balance is used above $2000 \mathrm{~m}$ elevation. This is in agreement with mass balance observations, where constant mass balances at high elevation are attributed to avalanche and wind transport (Greuell, 1992).

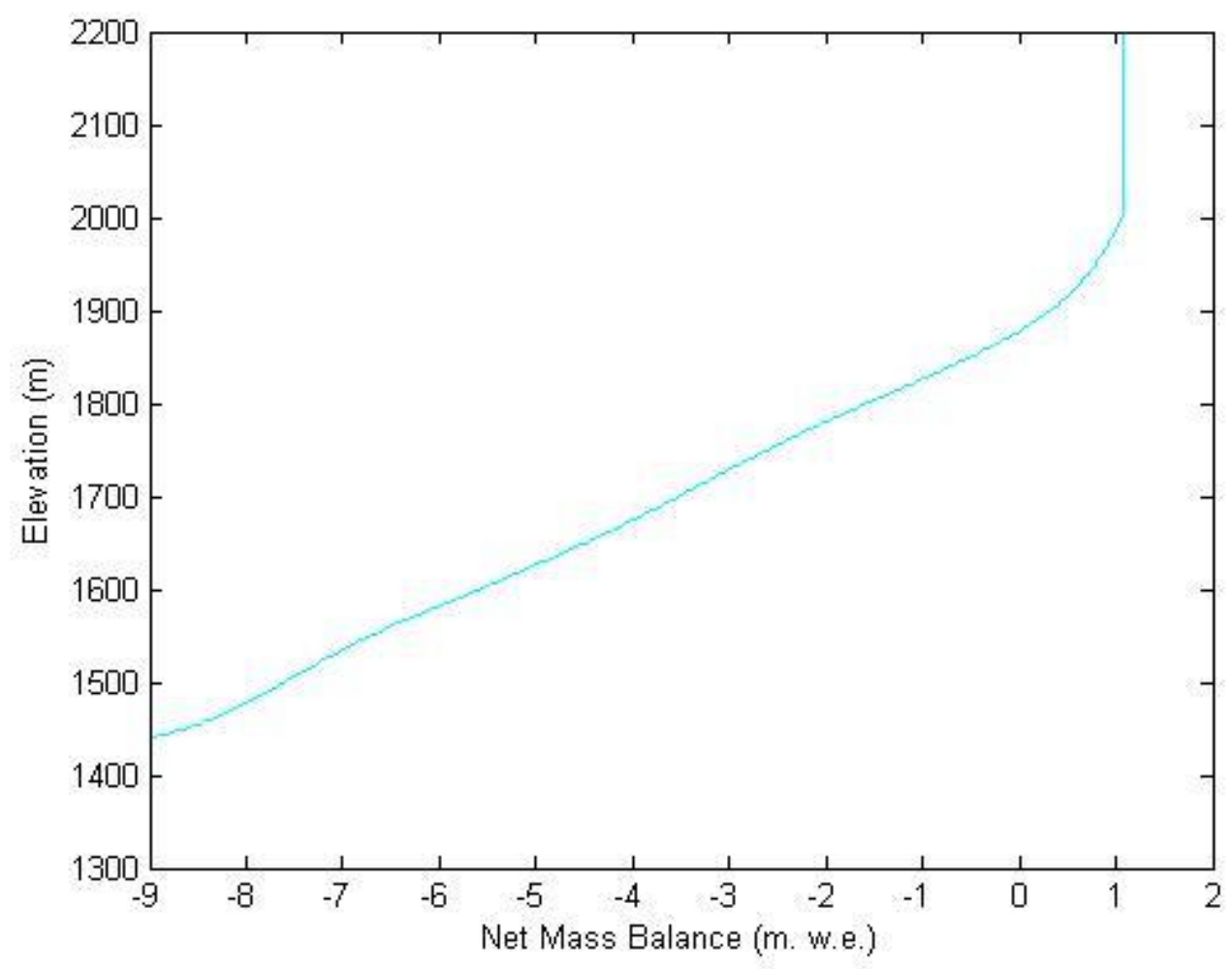

Figure 6. The mass balance curve used for the theoretical model glacier.

The mass balance history of the Nisqually Glacier remains largely indefinite partly because of the inaccessibility of the upper reaches of the glacier. Therefore, difficulties arise in correctly simulating the mass balance of the glacier with a numerical model. For this reason, a simple linear mass balance function is used to model the Nisqually Glacier in equilibrium. However, several obvious inaccuracies arise from using this scenario. The Nisqually Glacier is 
currently not in equilibrium. Further, the Nisqually Glacier is responding to both past and present climate and climate variations. The response time varies, but is approximately on the scale of several years to several decades (Nye, 1960). Thus, historical climate variations along with current climate define the present mass balance of the Nisqually Glacier. Comparison of the ELAs of today's glacier and the modeled glacier is therefore invalid.

The Nisqually Glacier model uses a linear function based on a precipitation lapse rate (P). The lapse rate is calculated from the slope of South Cascade Glacier mass balance data collected from Bidlake (2005, 2007, and 2010).

$$
f(z)=(P * z)-34.5
$$

The intercept of the function can be adjusted more negative or more positive in order to move the ELA up or down in elevation. Because the length of the model glacier is directly dictated by mass balance, an intercept of -34.5 is necessary to produce a $\sim 6.4 \mathrm{~km}$ glacier (figure 7).

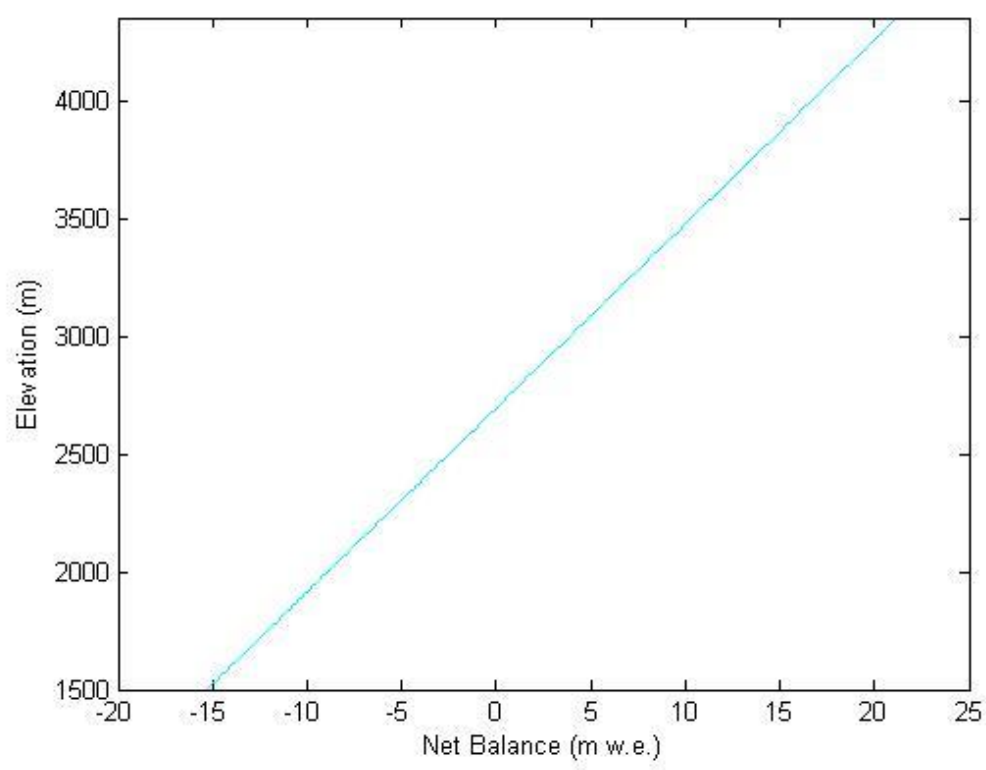

Figure 7. The linear mass balance function used for the Nisqually Glacier model. 


\subsection{Bed topography}

The bed topography of the theoretical model does not contain the intricacies involved in Nisqually Glacier model. It uses a flat bed on a 10 degree slope. The reason for this simplicity is in order to analyze pure kinematic wave behavior and that is not influenced by the effect of bed undulations and roughness. The bed topography for the upper $4.85 \mathrm{~km}$ of the Nisqually Glacier model is constructed from surface slope and ice thickness data from Allstadt et al. (2015).

Surface slope was derived from the Robinson et al. (2010) 2008 LiDAR DEM study (Allstadt et al., 2015). Subsequently, ice thicknesses were derived from both 2008 LiDAR DEM surface elevations (Robinson et al., 2010) and digitized and interpolated bed topography from Driedger and Kennard (1986) (Allstadt et al., 2015). 


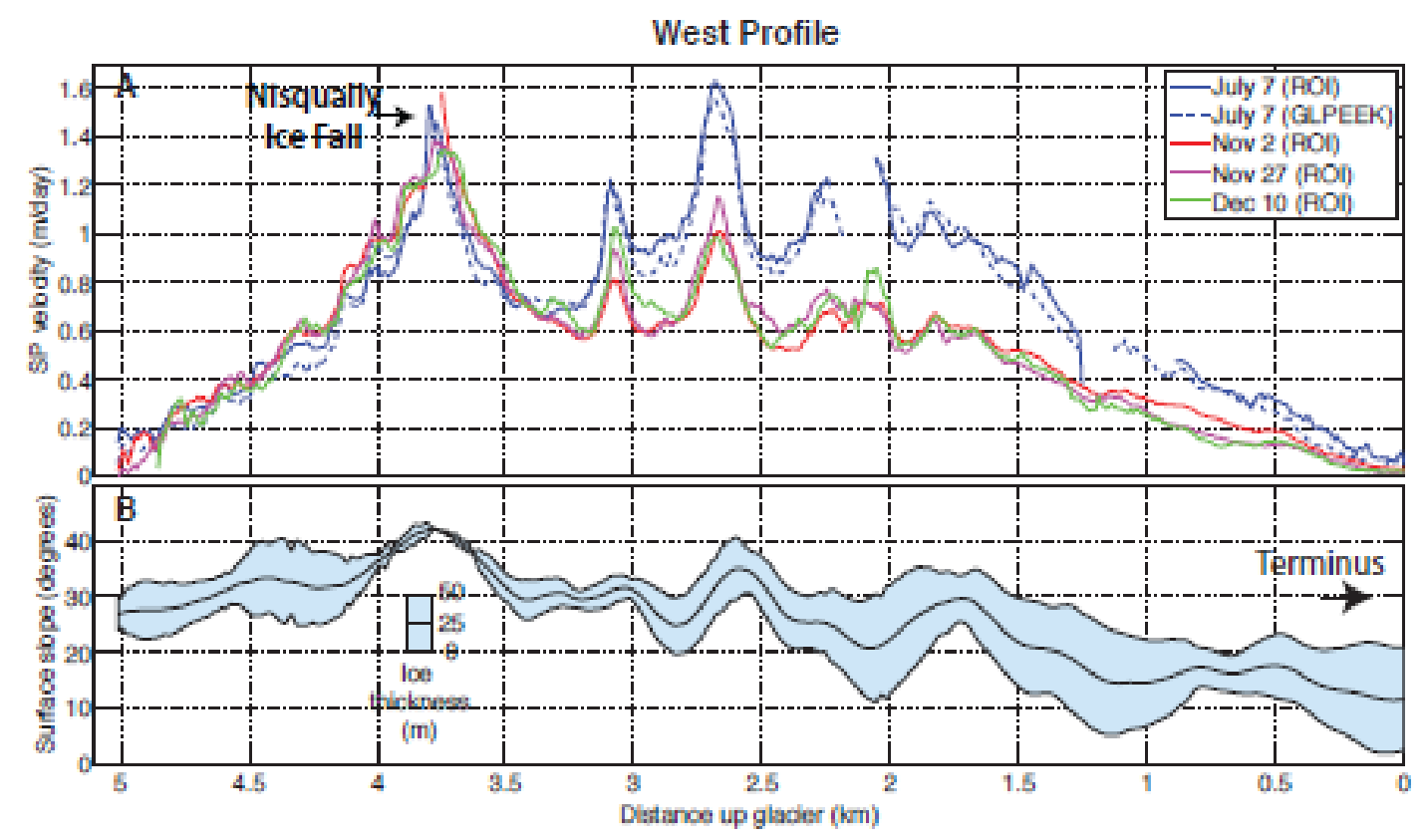

East Profile

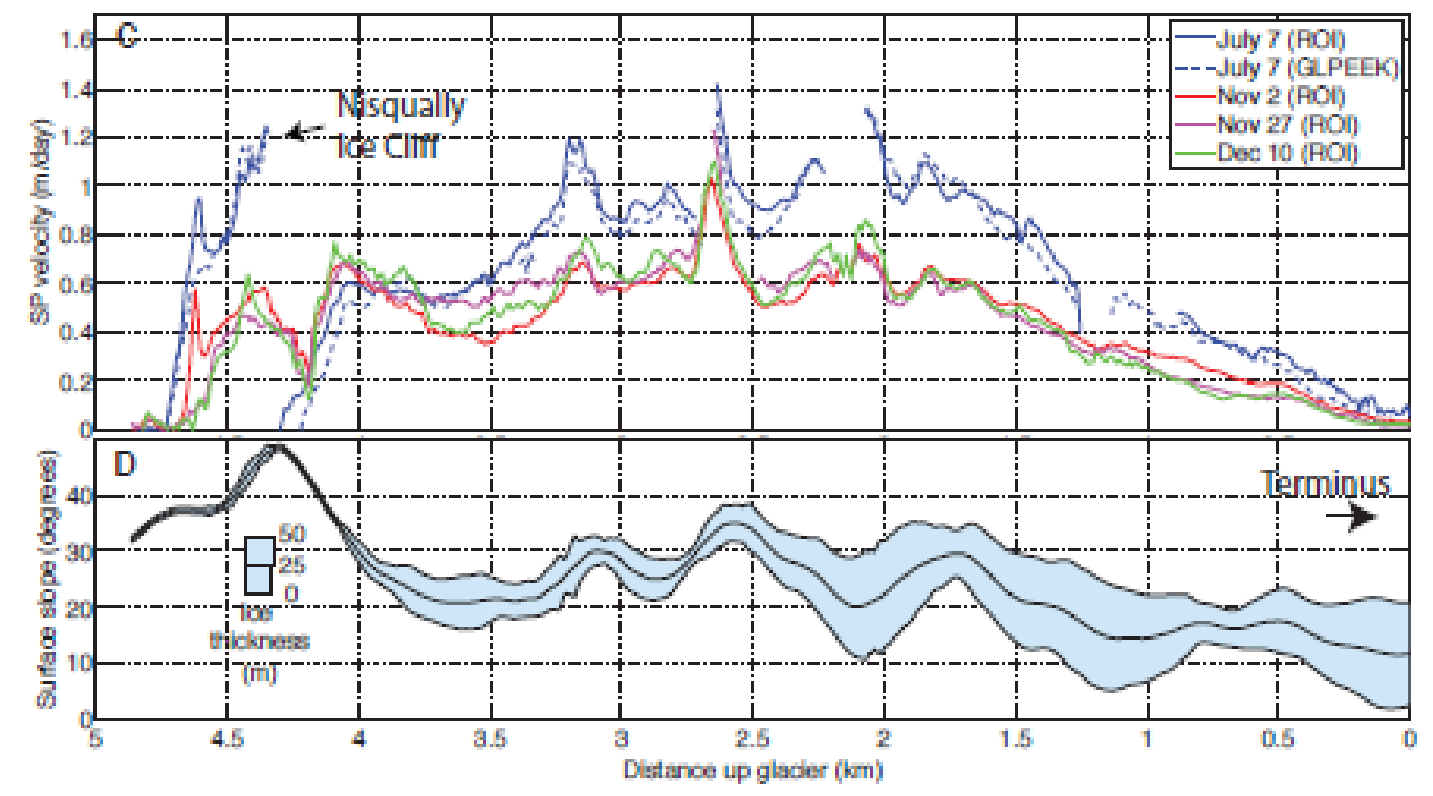

Figure 8. From Allstadt et al (2015), figure 6. (a) and (c): Slope parallel velocity profiles for the West and East Profile of the Nisqually Glacier, (b) and (d): surface slope and ice thickness for the West and East Profile. Surface slope is smoothed identically to that used for slope parallel corrections (see text), ice thicknesses are estimated from digitized basal contours from Driedger and Kennard (1986) and surface elevations from the 2008 LiDAR (Robinson et al., 2010). 


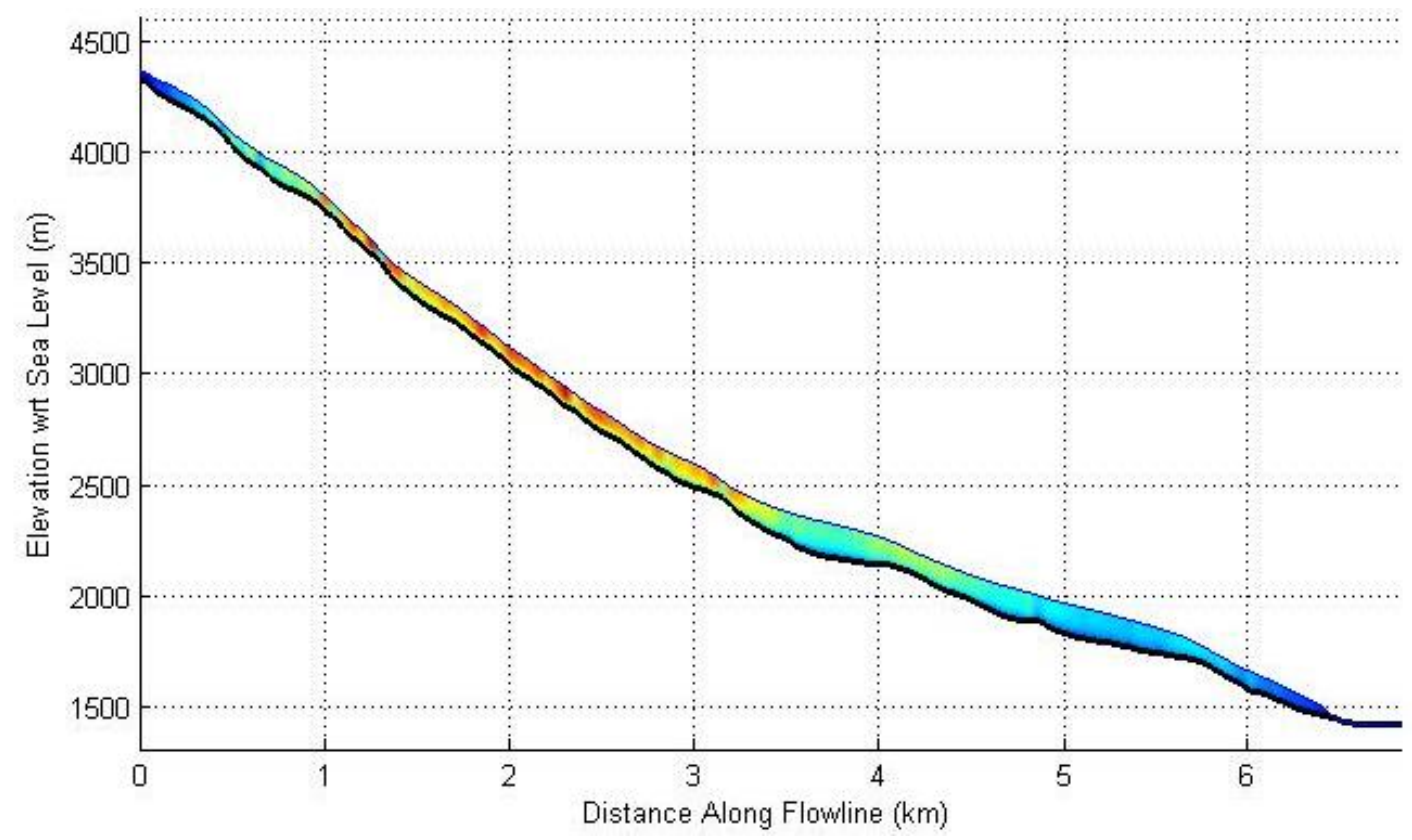

Figure 9. A plot showing the Nisqually Glacier model using the West Profile bed topography.

Within the upper reaches of the Nisqually Glacier are two defined branches. The eastern and western branches contain the Nisqually ice cliff and the high velocity Nisqually ice fall respectively (Allstadt et al., 2015). They are referred to as the East and West Profiles by Allstadt et al. (2015) (figure 8). The West Profile yields continuous ice existence and is therefore used in the Nisqually Glacier model (figure 9).

The lower $1.55 \mathrm{~km}$ of the Nisqually Glacier's bed topography is taken from figure 54 of Hodge (1972). Elevations are estimated from the centerline of the bed, and elevations between contours are approximated linearly (Hodge, 1972). 
The flow law, momentum balance, and continuity equations are defined from the PSU/UofC flowline model by Parizek et al. (2005). For simplification, flow in response to vertical shear stress assumes steady, uniform flow and is described by the following momentum balance (Parizek et al., 2005):

$$
\tau_{z x}(z)=-\rho_{i} g(s-z) \frac{\partial s}{\partial x}
$$

$\tau_{z x}$ signifies vertical shear stress, $\rho_{\mathrm{i}}$ signifies the density of ice, $g$ indicates gravitational acceleration, $s$ indicates ice surface elevation, and $z$ and $x$ indicate vertical and horizontal position respectively (Parizek et al., 2005).

The model uses a diffusion equation to approximate mass continuity,

$$
\frac{\partial h}{\partial t}=\frac{\partial}{\partial x}\left(D \frac{\partial s}{\partial x}\right)+\dot{A}-\dot{B}
$$

where a $h$ is ice thickness, $t$ is time, $D$ is effective diffusivity, $\dot{A}$ is surface ice-equivalent accumulation rate, and $\dot{B}$ is the basal melting rate (Parizek et al., 2005). In particular, $D$ is defined by equation 5 ,

$$
D\left(\frac{\partial s}{\partial x}\right)=-h \bar{u}
$$

where $\bar{u}$ is the depth-averaged ice velocity in the horizontal direction (Parizek et al., 2005).

Horizontal velocity is defined by equation 7 after equating equation 6 with shear strain rate, substituting for vertical shear stress in equation 3, and integrating (vertically) (Parizek et al., 2005). 


$$
\begin{gathered}
\dot{\varepsilon}_{i j}=A\left(T^{*}\right) \tau_{*}^{n-1} \tau_{i j}^{\prime} \\
u(z)=u(b)-2 \rho_{i} g \frac{\partial s}{\partial x} I(z)
\end{gathered}
$$

where $\dot{\varepsilon}_{i j}$ is strain rate, $\tau_{*}$ is effective shear stress, $\tau^{\prime}$ is deviatoric stress components, $b$ is basal ice elevation, $u$ is horizontal velocity, and $I(z)$ is the depth dependent deformation velocity (Parizek et al., 2005). I( $z$ ) is derived by equation 8.

$$
I(z)=\int_{b}^{z} A\left(T^{*}\right)\left(\rho_{i} g \frac{\partial s}{\partial x}\right)^{(n-1)}\left(s-z^{\prime}\right)^{n} d z^{\prime}
$$

where $T^{*}$ is homologous temperature and $A$ is the creep-rate prefactor (Parizek et al.,2005).

The model derives vertical velocity from incompressibility and vertical integration of equation 9. Note that $w$ represents vertical velocity.

$$
\begin{gathered}
\frac{\partial w}{\partial z}=-\frac{\partial u}{\partial x} \\
w(z)=w(b)-\int_{b}^{z} \frac{\partial z\left(z^{\prime}\right)}{\partial x} d z^{\prime}
\end{gathered}
$$

A more elaborate description and derivation of the equations used can be found in Parizek et al. (2005) and Parizek (2000). 


\subsection{Basal Sliding}

Basal sliding is a dominate component of alpine glacier surface velocities (Allstadt et al., 2015). Allstadt et al. (2015) found that sliding is responsible for around $91-99 \%$ of the measured velocity of the Nisqually Glacier (and proved that these approximations resembled estimates from Hodge (1974)). My Nisqually Glacier model uses the Budd-type parameterization for basal sliding $\left(u_{\text {sliding }}\right)$ of the following form (equation 11) from Allstadt et al. (2015):

$$
u_{\text {sliding }}=k * \frac{\tau_{d}^{m}}{N_{e f f}}
$$

$N_{\text {eff }}$ is the effective pressure at the glacier's base, $k$ is the coefficient that estimates a glacier's coupling strength to its bed, $m$ is the sliding law parameter, and $\tau_{d}$ is the gravitational driving stress. Equation 12 represents the gravitational driving stress $\left(\tau_{d}\right)$.

$$
\tau_{d}=\sin (\alpha) \rho_{i} g H
$$

$H$ represents local ice thickness, $\alpha$ is local surface slope, $g$ is gravitational acceleration, and $\rho_{i}$ is ice density. Allstadt et al. (2015) adjusted both $N_{\text {eff }}$ and $k$ in a basal sliding velocity model to produce results that most accurately matched the residual velocity (deformational velocity subtracted from observed velocity) (Allstadt et al., 2015). I use their November/December values, where $k=5.3^{*} 10^{-6} \mathrm{~ms}^{-1}$ and $N_{\text {eff }}=3.7 * 10^{5} \mathrm{~Pa}$. 


\subsection{Temperature Profile}

Temperate glaciers of the Cascade Range (Driedger and Kennard, 1986) have ice temperatures close to or at the melting point (Maohuan, 1990). For simplicity, the temperature profile for the model glacier and bedrock is set to a uniform $0^{\circ} \mathrm{C}$.

\subsection{Geothermal and Isostatic Responses}

The PSU/UofC flowline model is intended to model the Greenland Ice Sheet. To convert the model to simulate alpine glaciers, several main sections of the model are completely eliminated. Both geothermal and isostatic responses have less significance to alpine glacier studies and are unnecessary to include for the scope of the experiments.

\section{Model Kinematic Wave Formation}

There are two main properties of the model that I adjust in order to investigate kinematic wave behavior: mass balance and slope steepness. Mass balance is adjusted in both the theoretical and the Nisqually Glacier models. These experiments include changing both the duration and magnitude of the mass balance perturbation. Slope steepness is only adjusted in the theoretical model. By altering mass balance and slope steepness discretely, their effects on kinematic wave behavior is analyzed. 


\subsection{Altering the Mass Balance}

A uniform and instantaneous perturbation to the mass balance is forced upon the steady state modeled glacier (figure 10). The mass balance perturbation persists for a specified time interval over which the perturbation remains a constant value and terminates instantaneous. This method is used on both the theoretical and Nisqually glacier models. In order to investigate kinematic wave behavior, I use trials with various mass balance durations and magnitudes. The following lists the different trials:

- A 1 m. w.e. perturbation for 1 year

- A 1 m. w.e. perturbation for 3 years

- A 0.5 m. w.e. perturbation for 1 year

- A 0.5 m. w.e. perturbation for 3 years

All mass balance perturbations begin at year 5 of the numerical model. This allows the mocel to "spin-up" time so that the glacier is in a state of complete equilibrium before the mass balance perturbation begins. The model is run for 160 years and ice thickness and surface velocity are stored every 1-5 years. 


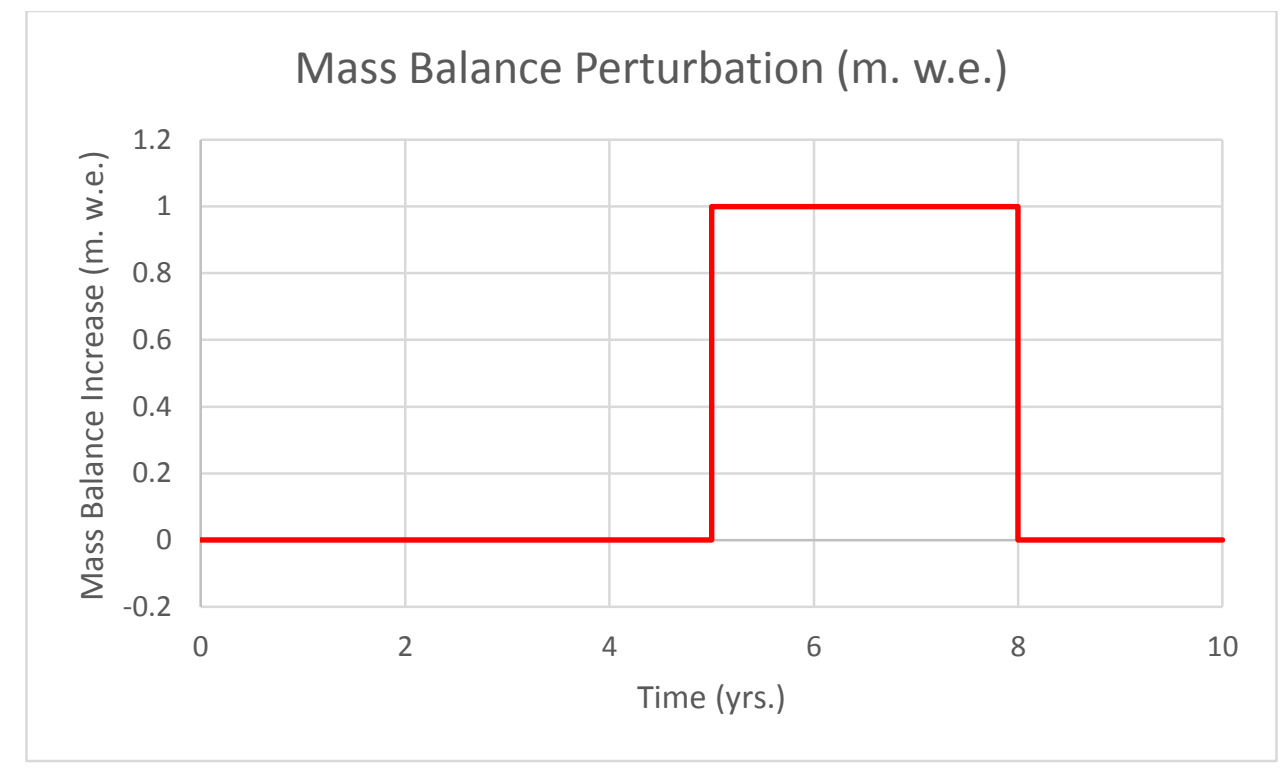

Figure 10. The uniform and instantaneous mass balance perturbation used to initiate kinematic wave formation. This is an example of a $1 \mathrm{~m}$. w.e. perturbation lasting for 3 years.

\subsection{Altering Slope steepness}

To assess the potential effects of slope steepness on kinematic wave behavior, a slope of 8 degrees is compared to the 10 degree standard theoretical model. Identical mass balance perturbations are used for each trials so that effects exclusively related to slope steepness on kinematic wave formation are analyzed. Note that when slope steepness is lessened, a thicker, longer glacier is created. For trials of differing slope steepness, the same ELA is used and the 8 degree slope model glacier is $\sim 7.6 \mathrm{~km}$. 


\section{Model Results for Theoretical Glacier}

To investigate kinematic wave behavior, the response of ice thickness to a mass balance perturbation is defined based off of the difference in ice thickness at time $n$ years (where $n=0, \ldots$ ., 160 years) compared to steady-state ice thickness.

Change in ice thickness is examined in figure 11. The overall behavior of the theoretical model is similar to that found by Van de Waal and Oerlemans (1995). From both my results and Van de Waal and Oerlemans (1995), the terminus region of the glacier experiences the most pronounced response, whereas upglacier has a less obvious response. Van de Waal and Oerlemans (1995) point out that this distinct increase in ice thickness at the terminus is due to an increase in mass flux in the model and subsequent advance of the glacier. Van de Waal and Oerlemans (1995) also state that the instability at the terminus is relieved only by the kinematic wave's arrival. These responses can be examined in one of several ways. During a uniform increase in mass balance, all areas of the glacier experience more accumulation (or less ablation). Ice flux into a particular cross section of the glacier is greater than before, and resultant thickening occurs. The greater ice flux also produces higher velocities, initiating the kinematic wave. Because it is a uniform increase, all areas on the glacier respond to their upglacier counterpart (except at the very head of the glacier). Even after the perturbation ends, parts of the glacier are still responding to this greater ice flux. However, there is a succession of changes that occur. The head of the glacier, which has no upglacier influences, immediately responds to the termination of the mass balance increase. At this same time, the downglacier sections down to the terminus are still responding to the increase in ice flux that occurred previously. It is not until the succession of responses from the glacier head downglacier reach the terminus area that the instability in ice thickness increase is relieved. This place on the surface of the glacier where the 
response of upglacier sections has ended and where the response of downglacier sections is still occurring propagates downglacier and represents the wave front of the kinematic wave. This process explains Van de Waal's and Oerlemans' (1995) conclusion that glacier stability is restored from the glacier head sequentially down to the terminus.
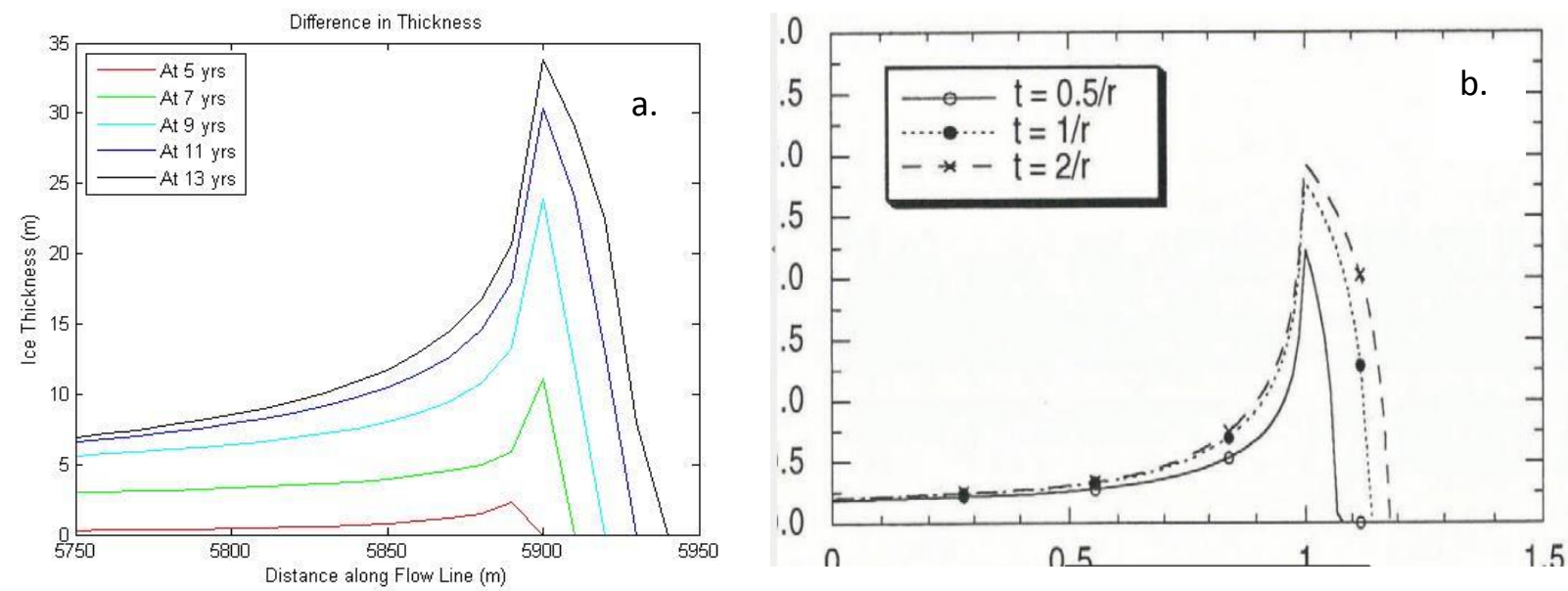

Figure 11. The mass balance perturbation as a kinematic wave (a). The terminus change is the most prominent. The form is similar to that found by Van de Waal and Oerlemans (1995 (b)).

Change in ice thickness and surface elevation are examined in figure 12. Notice that for a mass balance perturbation of $1 \mathrm{~m}$. w.e. over 3 years, the ice thickness only marginally increases in the accumulation zone. The effects are largely concentrated to the glacier terminus. Here, the ice thickness increases to a maximum of $\sim 40 \mathrm{~m}$ at $20 \mathrm{~m}$ up glacier of the terminus. This maximum occurs 12 years after the termination of the perturbation and 15 years after the beginning of the perturbation. A transitory advance in glacier length of $50 \mathrm{~m}$ can be observed. The glacier begins to retreat after and does not reach complete equilibrium until $\sim 120$ years after the perturbation ends. Glacier equilibrium is restored from the head down to the terminus, with 
the terminus being the last part of the glacier to reestablish equilibrium. This is in congruence with results from Van de Waal's and Oerlemans' (1995) Hintereisferner experiment.

In another trial, a mass balance perturbation of $1 \mathrm{~m}$. w.e. for 1 year is applied to the theoretical glacier model. A maximum ice thickness change of $\sim 22 \mathrm{~m}$ occurs $20 \mathrm{~m}$ upglacier of the terminus 15 years after the beginning of the mass balance perturbation and 14 years after its termination. The transition back to equilibrium begins after and equilibrium is restored $~ 110-120$ years after the perturbation.

For a mass balance perturbation of $0.5 \mathrm{~m}$. w.e. for 3 years, a maximum ice thickness increase of $\sim 28 \mathrm{~m}$ occurs $30 \mathrm{~m}$ upglacier of the terminus. Similar equilibrium restoration times are observed for the trials with a $1 \mathrm{~m}$. w.e. perturbation. In the final experiment with a mass balance perturbation of $0.5 \mathrm{~m}$. w.e. for 1 year, a maximum ice thickness of $\sim 14 \mathrm{~m}$ is observed 10 $\mathrm{m}$ upglacier of the terminus. The restoration back to equilibrium again ensues after a $10 \mathrm{~m}$ advance 15 years after the beginning of the perturbation. This takes $\sim 110$ years. 

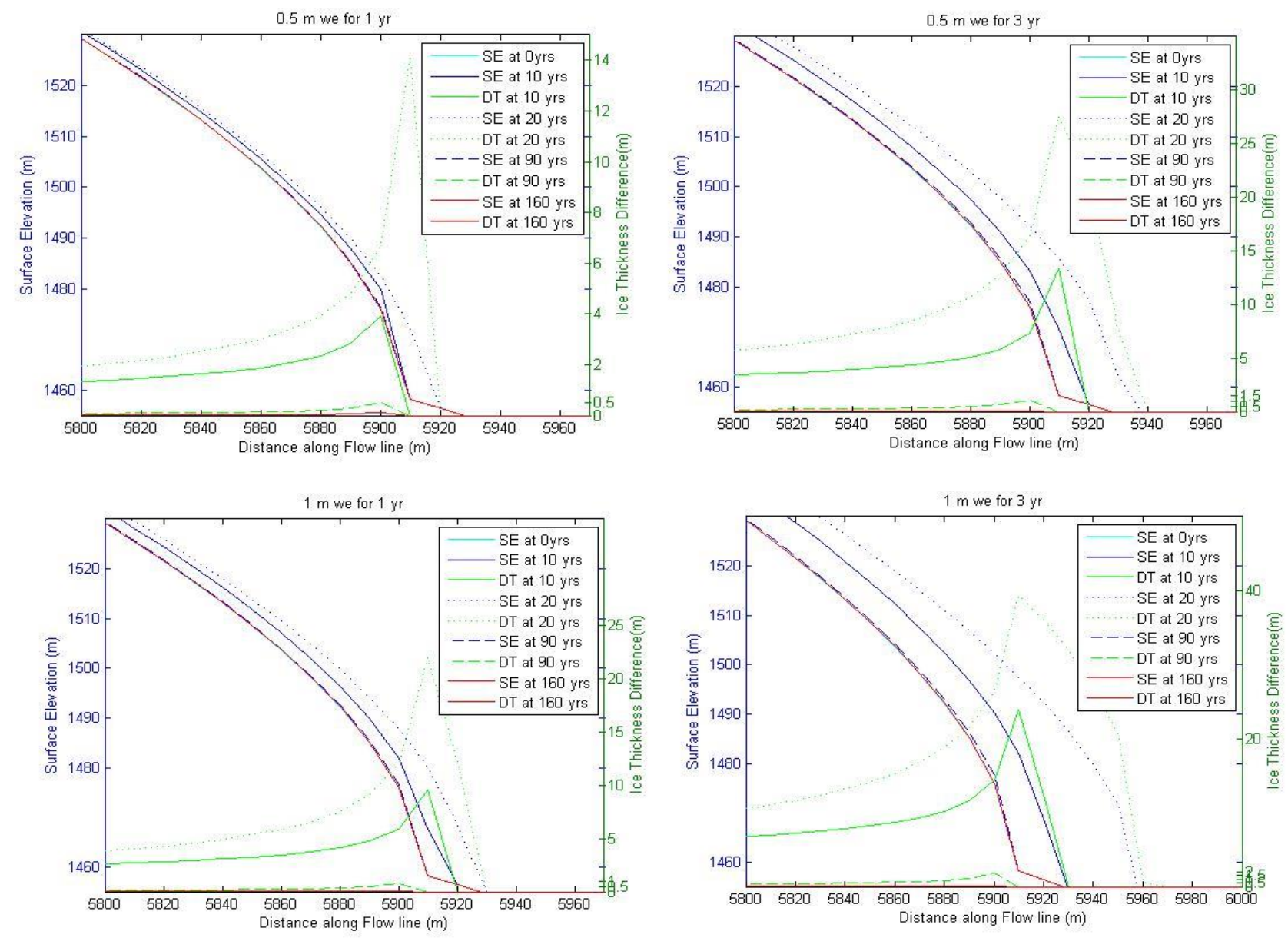

Figure 12. Surface elevation and change in ice thickness for different mass balance perturbations.

The magnitude and duration of the mass balance perturbation determine the extent of ice thickness increase and glacier advance. The glacier's response to $1 \mathrm{~m}$. w.e. for 1 year is roughly the same as to $0.5 \mathrm{~m}$. w.e. for 3 years. This suggests that an observed kinematic wave could have several means of forming from various duration and quantity inputs. Therefore, both magnitude and duration of the perturbation are closely interrelated properties that affect and may hinder identifying specific conditions that form a particular kinematic wave. 
After the passage of the kinematic wave front, the glacier immediately transitions back towards equilibrium. The time it takes to reach equilibrium depends on the position along the flowline. As stated before, equilibrium is restored from the glacier head to the terminus. From figure 13a, equilibrium is reached around model year 80-85 at $2.15 \mathrm{~km}$ along the flowline (halfway between the head and the ELA). Equilibrium is reached around model year 95-100 at $4.25 \mathrm{~km}$ along the flowline (the ELA) (figure 13b) and around model year 115-120 at $5.10 \mathrm{~km}$ along the flowline (halfway between the ELA and the terminus) (figure 13c). Figure 13d illustrates the advances and subsequent retreat of the glacier over $5.92 \mathrm{~km}$ along the flowline.
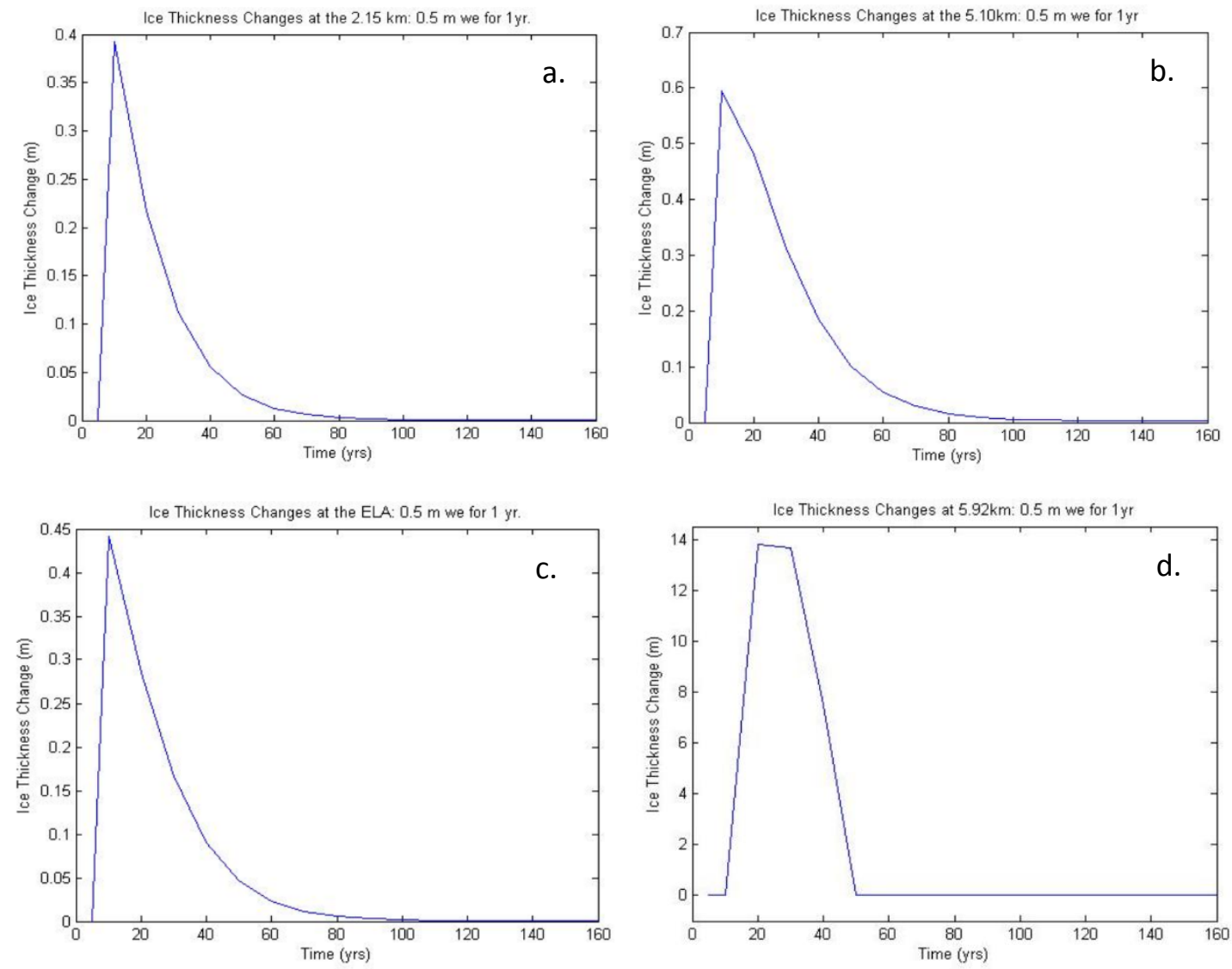

Figure 13. The change in ice thickness through time at $2.15 \mathrm{~km}$, the ELA, $5.10 \mathrm{~km}$ down from the head of the glacier, and just beyond the terminus of the time $=0 \mathrm{yrs}$ glacier. 
In order to gain insight into how slope steepness affects kinematic wave formation and propagation, experiments on a slope of 8 degrees is compared to those on a 10 degree. Two experiments are used for the comparison $-0.5 \mathrm{~m}$. w.e. perturbation for 1 year and $1 \mathrm{~m}$. w.e. perturbation for 3 years. The $0.5 \mathrm{~m}$. w.e. perturbation for 1 year shows a response of $\sim 11 \mathrm{~m}$ ice thickness and a temporary advance of $10 \mathrm{~m}$. The glacier completely restores equilibrium after 90-100 years. Here the ice thickness response is noticeably less than for the same experiment for the theoretical model on a 10 degree slope, where the increase was $\sim 14 \mathrm{~m}$. In addition, the response time is less than for the 10 degree slope experiment ( 90-100 years compared to $\sim 110$ years). These differences may be explained by the slope steepness used for each experiment. An 8 degree slope produces a thicker, longer glacier. The same mass balance perturbation would experience more diffusion than with the 10 degree slope model glacier. However, note that for a $1 \mathrm{~m}$. w.e. perturbation for 3 years, the results for the maximum ice thickness change, maximum advance, and restoration time to equilibrium are comparable to those for the 10 degree slope experiment. According to these experiments, slope steepness controls the glacier's response to a small mass balance perturbation: steeper slopes show a more prominent response. However, the slope steepness seems to have little effect on glacier response with perturbations that have more extreme durations and magnitudes. However, this latter conclusion should be further studied. 

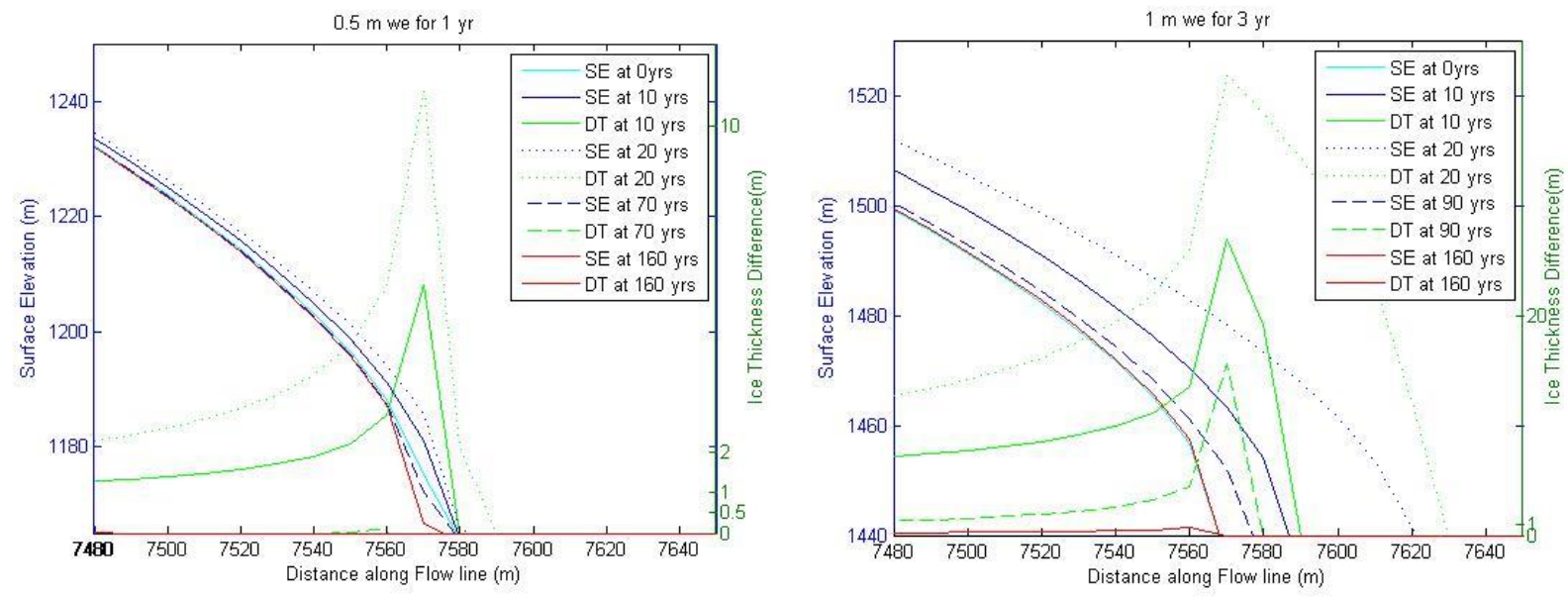

Figure 14. Experiments using $0.5 \mathrm{~m}$. w.e. perturbation for 1 years and $1 \mathrm{~m}$. w.e. perturbation for 3 years on an 8 degree slope.

\section{Model Results for Nisqually Glacier}

To get an understanding of kinematic wave behavior on present day Nisqually Glacier, a set of experiments use the Nisqually Glacier model. In particular, what mass balance perturbation (magnitude and duration) would produce a kinematic wave on present-day Nisqually similar to those of the 1940s-1960s? Again, kinematic wave behavior is examined based on the response of ice thickness to a mass balance perturbation. The change in ice thickness is defined at time $n$ years (where $n=0, \ldots, 160$ years) compared to steady-state ice thickness.

In order to compare the modeled Nisqually Glacier ice elevation change to the ice-surface altitude surveys on Nisqually Glacier of Heliker et al. (1984), Profiles 1, 2, and 3 locations are used. The three locations are stated in terms of position from the 1976 terminus. Using data from 
Skloven-Gill and Fountain (2015), each profile is transformed from the 1976 position to presentday location on the modeled glacier. The ratio denotes profile location divided by glacier length.

Table 2. The transformation of Profiles 1, 2, and 3 from the 1976 glacier to the present-day glacier.

\begin{tabular}{|l|c|c|c|}
\hline & Ratio & 1976 Position Upglacier (m) & Present-day Position Upglacier (m) \\
\hline \hline Profile 1 & 0.0796 & 550 & 509.44 \\
\hline Profile 2 & 0.1881 & 1300 & 1203.8 \\
\hline Profile 3 & 0.3429 & 2370 & 2194.6 \\
\hline
\end{tabular}

The overall response of a mass balance perturbation on the Nisqually Glacier model is similar to that for the theoretical model (figure 15). The terminus region of the glacier experiences the most pronounced response, whereas upglacier has a less obvious response. However, the shape of the perturbation differs mostly in smoothness of the response of ice elevation in the accumulation and lower ablation zone. This is largely explained by the unevenness of the Nisqually Glacier bed topography, which is one of the main differences between the theoretical and Nisqually glacier models. The response times for each of the four trials in figure 13 is $\sim 5-25$ years depending on location and experiment (much less than the response times of $\sim 80$ years for the theoretical model experiment), suggesting rapid diffusion of the kinematic waves.

Table 3 shows the maximum ice elevation changes at Profiles 1, 2, and 3 for each mass perturbation experiment. Note that for the trials examined in figure 14, the maximum ice elevation change is only $6.20 \mathrm{~m}$ at Profile 1 for $1 \mathrm{~m}$. w.e. for 3 years. This minimal ice elevation change is drastically dissimilar compared to Heliker et al.'s (1984) reported maximum ice elevation change of $25 \mathrm{~m}$ at Profile 3 between 1944-1951 and $31 \mathrm{~m}$ at Profile 2 in 1957. Several more experiments (figure 16) aim to reproduce this wave: 
- A 2 m. w.e. perturbation for 3 years

- A 4 m. w.e. perturbation for 3 years

- A 6 m. w.e. perturbation for 3 years

The ice elevation changes for these experiments are shown in figure 16. From table 3 , the best approximation to the 1957 wave is the $6 \mathrm{~m}$. w.e. perturbation for 3 years experiment. This produced a maximum ice elevation change of $27 \mathrm{~m}$ at Profile 2, $28 \mathrm{~m}$ at Profile 1, and $12.1 \mathrm{~m}$ at Profile 1. The changes are slightly less than that largest kinematic wave observed on the Nisqually Glacier. However, the mass balance experiments that most closely produced the best approximations (such as a $6 \mathrm{~m}$. w.e. perturbation for 3 years) are rather unreasonable for physical existence. Thus, it is concluded that mass balance magnitude and duration are by themselves insufficient to explain the formation of the kinematic waves on the Nisqually Glacier. 

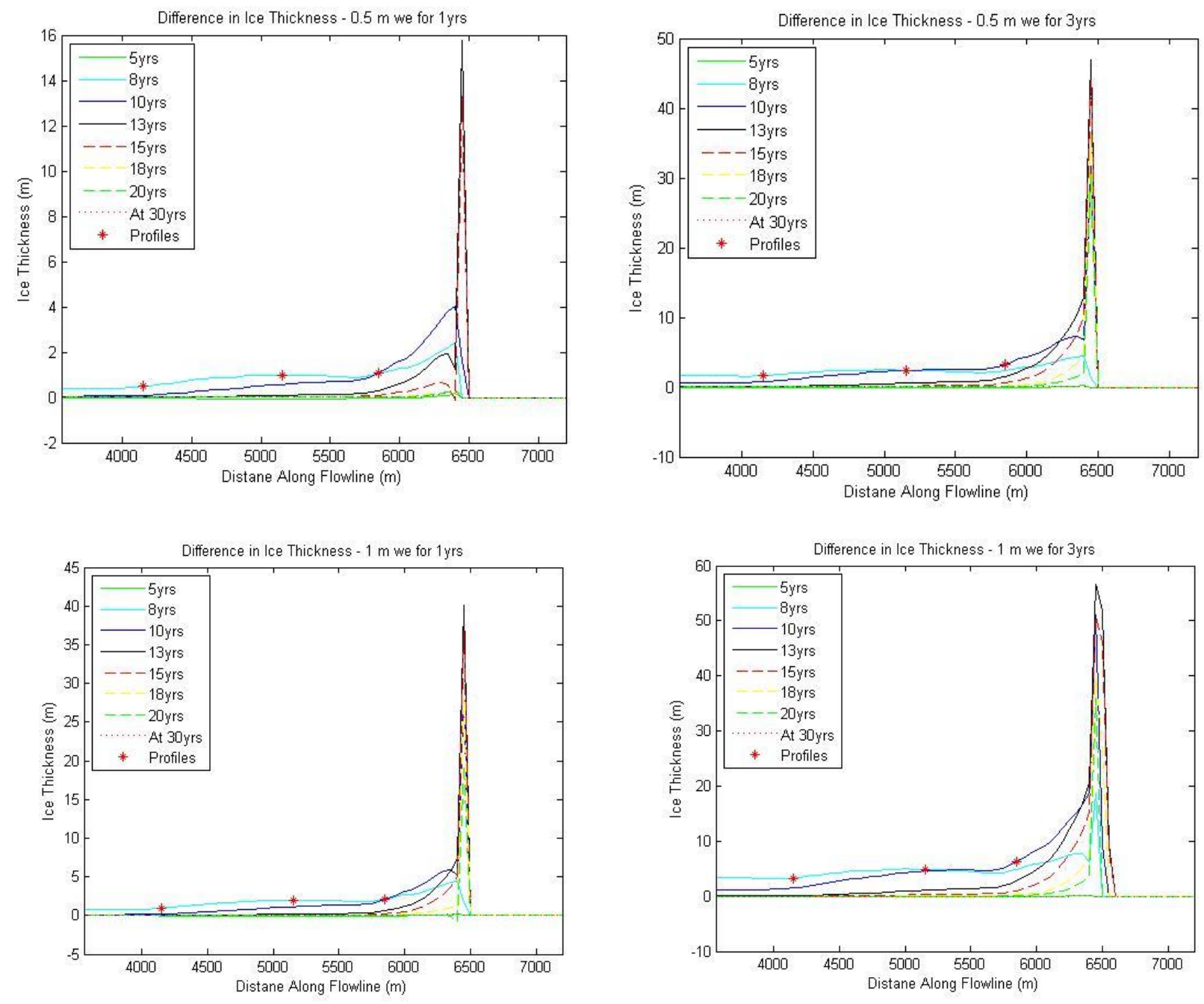

Figure 15. Mass balance perturbations for $0.5 \mathrm{~m}$. w.e. for 1 year and 3 years and $1 \mathrm{~m}$. w.e. for 1 year and 3 years. Profiles 1, 2, and 3 are the successively upglacier red stars (respectively). 

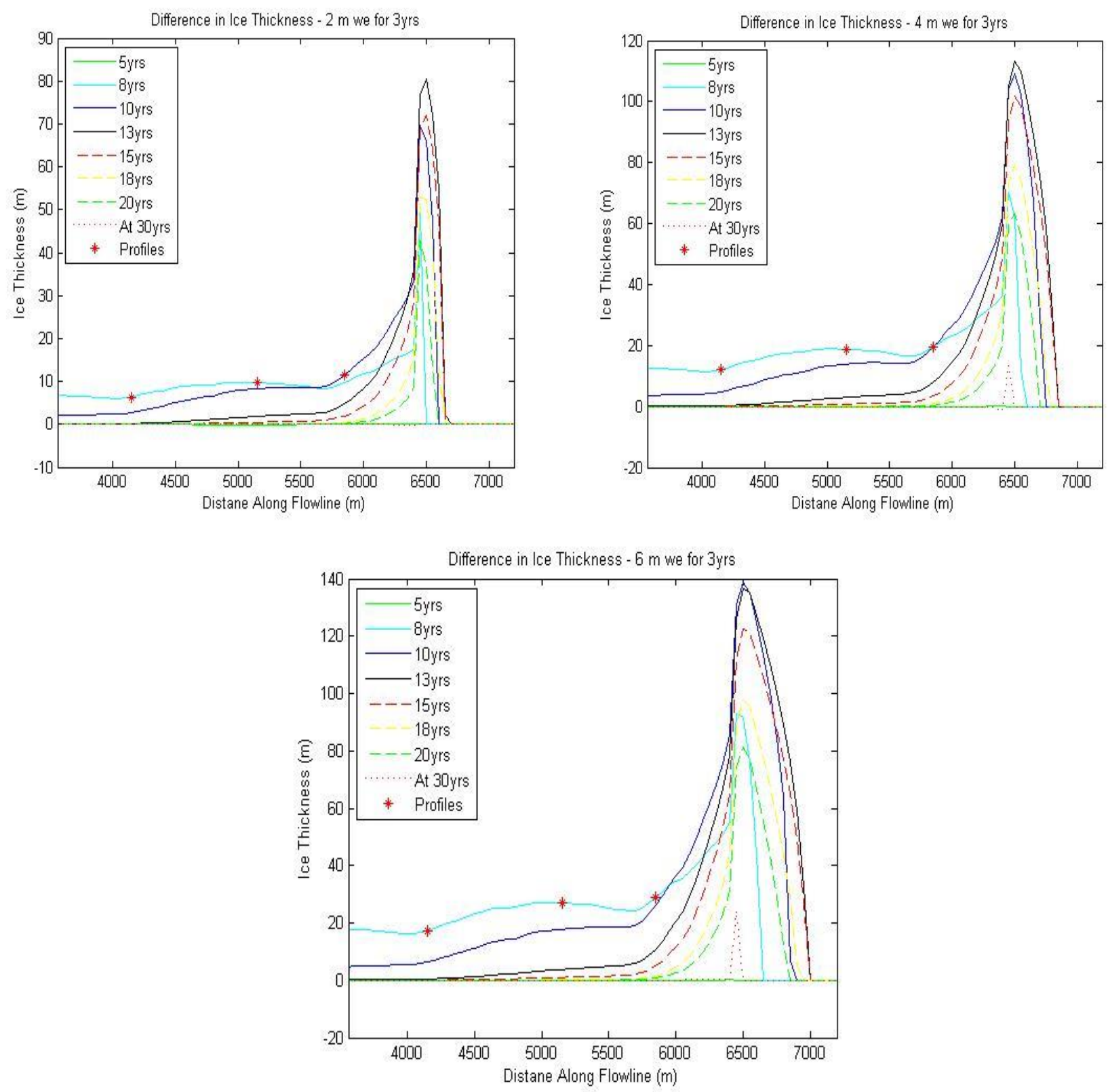

Figure 16. Mass balance perturbation of 2 m. w.e., 4 m.w.e., and 6 m.w.e. for 3 years. 
Table 3. Results from the Nisqually glacier model trials for the elevation change of Profiles 1, 2, and 3.

\begin{tabular}{|c|c|c|c|}
\hline Mass Balance Perturbation & Profile 1 Max Elevation Change (m) & Profile 2 Max Elevation Change (m) & Profile 3 Max Elevation Change (m) \\
\hline \hline 0.5 m. w.e., 1yr & 1.05 & 1.00 & 0.46 \\
\hline 0.5 m. w.e., 3yrs & 3.20 & 2.35 & 1.60 \\
\hline 1 m. w.e. , 1yr & 2.10 & 2.00 & 0.93 \\
\hline 1 m. w.e., 3yrs & 6.20 & 4.90 & 3.20 \\
\hline 2 m. w.e., 3yrs & 11.40 & 9.70 & 18.80 \\
\hline 4 m.w.e., 3yrs & 19.50 & 27.00 & 12.10 \\
\hline 6 m.w.e., 3yrs & 28.80 & & 12.10 \\
\hline
\end{tabular}

The change in ice elevation through time for Profiles 1, 2, and 3 are shown in figure 17. Note that the maximum response successively travels downglacier, illustrating kinematic wave propagation. For the experiment of $0.5 \mathrm{~m}$. w.e. for 1 year, the maximum change occurs at year 7 for Profile 3, year 8 for Profile 2, and year 9 for Profile 3 (table 4). These changes are 1 year, 2 years, and 3 years respectively after the termination of the mass balance perturbation. The experiment of $4 \mathrm{~m}$. w.e. for 3 years shows a similar trend, with a maximum response at year 8 for Profiles 3, year 8.5 for Profile 2, and year 9.5 for Profile 1 ( 0 years, 0.5 years, and 1.5 years respectively after the mass balance termination). The faster arrival time to Profile 2 suggests a higher kinematic wave velocity. Table 5 displays approximate mean wave speed. Mean Wave Speed 1 denotes the average velocity of the kinematic wave from Profile 2 to Profile 1 , and Mean Wave Speed 2 denotes the average velocity of the kinematic wave from Profile 3 to Profile 2. The wave velocities approximately match the velocity of kinematic waves observed on glaciers. For example, the kinematic wave of 1891-1899 on Mer de Glace had a wave velocity of $800 \mathrm{ma}^{-1}$ (Van de Waal and Oerlemans, 1995). However, Heliker et al. (1984) state lower velocities for the kinematic waves on the Nisqually Glacier. Both observed waves reportedly traveled $\sim 380-760 \mathrm{ma}^{-1}$ from Profile 2 to Profile 1 and $\sim 158-180 \mathrm{ma}^{-1}$ from Profile 3 to Profile 2. 
Note that the comparison is not completely equivalent. The model Nisqually Glacier simulates the present-day condition, whereas Heliker et al. (1984) reports the 1940s-1960s condition. Further, both the estimation of profile locations to the present-day glacier and the field data collected from the 1940s-1960s kinematic waves may have produced inexact results. However, the model results for kinematic wave velocity are not unreasonable and provide some insight into kinematic wave propagation. By examining table 4, the duration of the mass balance perturbation affects the occurrence of maximum ice elevation. For example, mass balance perturbations for a 3 year duration have a maximum wave amplitude at Profile 3 arrive at year 8 (the year at which the perturbation terminates). In contrast, mass balance perturbation for a 1 year duration have a maximum wave amplitude at Profile 3 arrive at year 7 (one year after the perturbation terminates). The magnitude of the mass balance perturbation also affects the arrival of the kinematic wave at the three profiles (and thus the wave velocity). Higher magnitudes result in generally faster arrival from one profile to the next. For example, the perturbation experiment with 2 m. w.e. for 3 years shows the arrival of the kinematic wave at Profile 3, 2, and 1 to be at year 8 , year 8.5 , and year 9.5 respectively ( 0 years, 0.5 years, and 1.5 years after the mass balance perturbation terminates). The perturbation experiment with $4 \mathrm{~m}$. w.e. for 3 years shows the arrival at Profiles 3, 2, and 1 to be at year 8 , year 8.25, and year 9 respectively ( 0 years, 0.25 years, and 1 year after the mass balance perturbation terminates). The change in the arrival times can be explained by the correlation between increased perturbation magnitude and high wave velocities. 

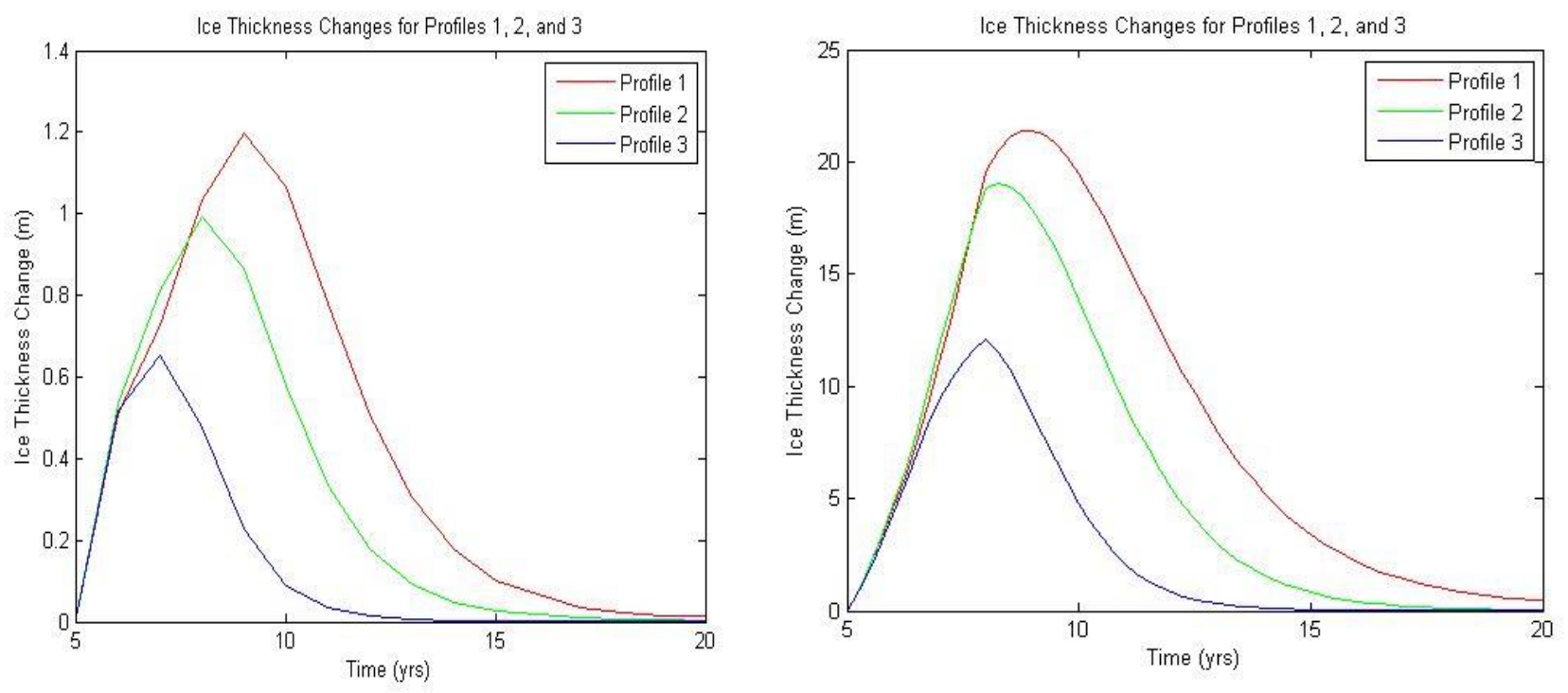

Figure 17. Ice elevation change of Profiles 1, 2, and 3 through time for two experiments: $0.5 \mathrm{~m}$. w.e. for 1 year and $4 \mathrm{~m}$. w.e. for 3 years (from left to right).

Table 4. The approximate arrival times (in model years) for the Nisqually Glacier experiments. Note that the mass balance perturbation begins at year 5 and ends either at year 6 or year 8 for the various experiments.

\begin{tabular}{|l|c|c|c|}
\hline \multicolumn{1}{|c|}{ Trial } & Profile 3 Arrival (yrs) & Profile 2 Arrival (yrs) & Profile 1 Arrival (yrs) \\
\hline \hline 0.5 m. w.e. for 1 year & 7 & 8 & 9 \\
\hline 0.5 m. w.e. for 3 years & 8 & 9 & 9.75 \\
\hline 1 m. w.e. for 1 year & 7 & 8 & 9 \\
\hline 1 m. w.e. for 3 years & 8 & 8.75 & 9.75 \\
\hline 2 m. w.e. for 3 years & 8 & 8.5 & 9.5 \\
\hline 4 m. w.e. for 3 years & 8 & 8.5 & 9.5 \\
\hline 6 m. w.e. for 3 years & 8 & 8 & 8.5 \\
\hline
\end{tabular}


Table 5. Approximate wave speeds for each Nisqually Glacier model experiment.

\begin{tabular}{|c|c|c|}
\hline Trial & Mean Wave Speed 1 $\left(\mathrm{ma}^{-1}\right)$ & Mean Wave Speed 2 $\left(\mathrm{ma}^{-1}\right)$ \\
\hline \hline 0.5 m. w.e. for 1 year & 700 & 1000 \\
\hline 0.5 m. w.e. for 3 years & 700 & 1333 \\
\hline 1 m. w.e. for 1 year & 700 & 1000 \\
\hline 1 m. w.e. for 3 years & 933 & 1000 \\
\hline 2 m. w.e. for 3 years & 1400 & 1000 \\
\hline 4 m. w.e. for 3 years & 2800 & 1333 \\
\hline 6 m. w.e. for 3 years & $>2800$ & 2000 \\
\hline
\end{tabular}

A transitory advance occurs in response to kinematic wave propagation through the Nisqually Glacier's terminus. The total amount of advance depends on the duration and magnitude of the mass balance perturbation. Three experiments are chosen to compare terminus behavior: $0.5 \mathrm{~m}$. w.e. perturbation for 1 year, $2 \mathrm{~m}$. w.e. perturbation for 3 years, and $6 \mathrm{~m}$. w.e. perturbation for 3 years (figure 18). From the $0.5 \mathrm{~m}$. w.e. perturbation for 1 year, the maximum of the transitory advance occurs $\sim$ year 15 ( 7 years after the perturbation terminates). This rather minimal increase of mass balance produces a total length change of $50 \mathrm{~m}$. The experiments 2 m.w.e. and 6 m.w.e. perturbation for 3 years (figure 18) produce maximum advances of $200 \mathrm{~m}$ and $550 \mathrm{~m}$ respectively from the initial stable length. According to the results of the model, kinematic wave propagation through the terminus of the glacier can produce significant glacier response. Even small increases in the mass balance of $0.5 \mathrm{~m}$. w.e. for 1 year can cause obvious glacier advance. This may explain the advances of the Nisqually Glacier through the late $1800 \mathrm{~s}$ to 1900s. For example, from 1857-2002, the Nisqually Glacier advanced a total of $294 \mathrm{~m}$ (Krimmel, 2002). This was perhaps previously confounding when comparing the behavior of the Nisqually Glacier to other glaciers that were experiencing retreat. However, the anomalous 
historical advances of the Nisqually Glacier are confidently explained by the sensitivity of glacier response to even slight positive perturbations in mass balance.
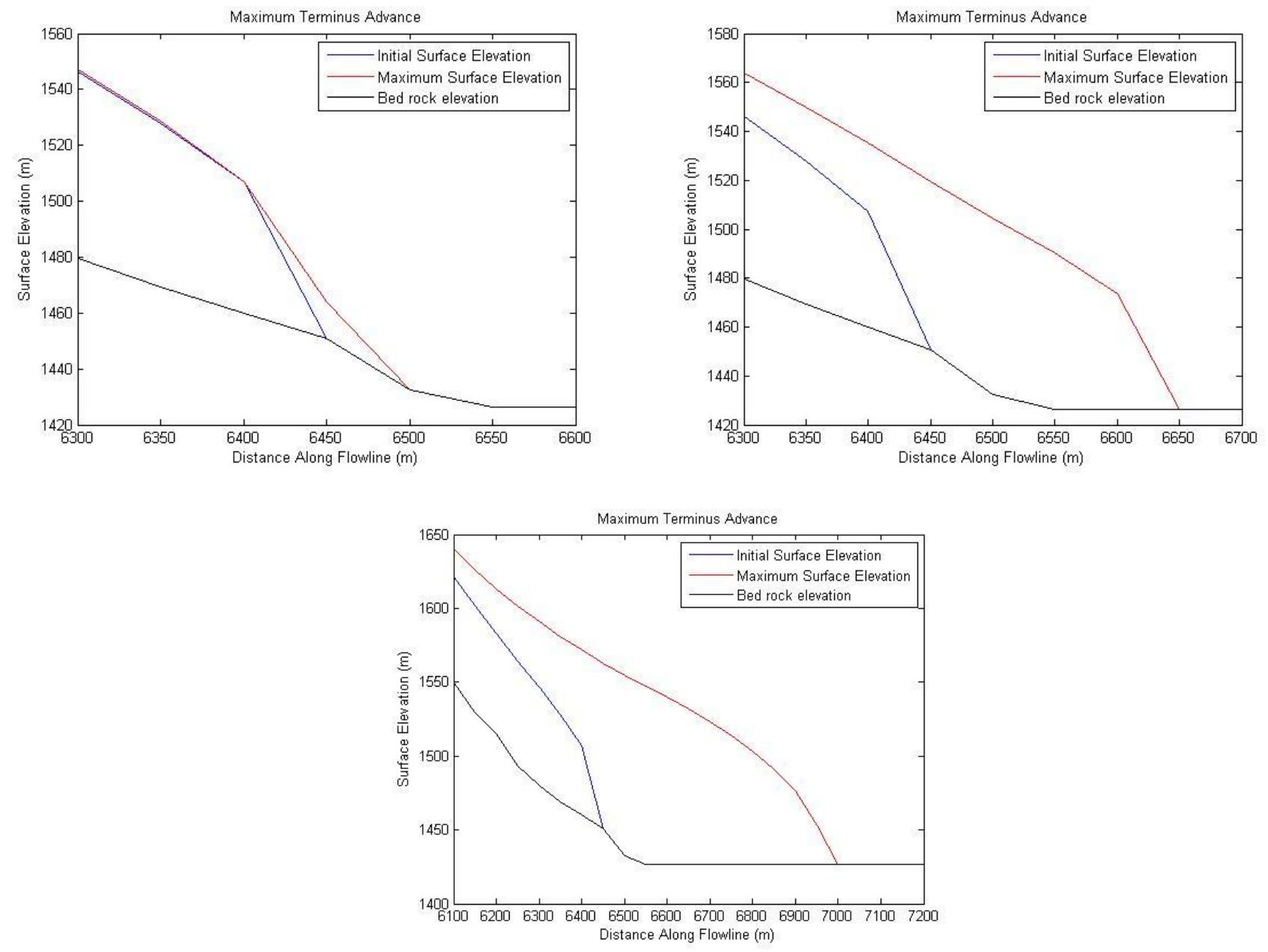

Figure 18. The terminus behavior for three Nisqually Glacier model experiments. From left to right and top to bottom: maximum advance for $0.5 \mathrm{~m}$. w.e. perturbation for 1 year, maximum advance for 2 m.w.e. for 3 years, and maximum advance for $6 \mathrm{~m}$. w.e. for 3 years. 


\section{Conclusion}

From this study, kinematic wave behavior is dictated by several factors. Both duration and magnitude of a mass balance perturbation affect the size of the wave, the amount of glacier advance, and the restoration time back to equilibrium. Larger durations and magnitudes produce a more prominent glacier response and various sets of perturbation duration and magnitude could form a similar observed kinematic wave. In addition, this study suggests that kinematic waves appear to exist at all scales. Mass balance perturbation of greater than $0.5 \mathrm{~m}$. w.e. for 1 year produce kinematic wave response, such as glacier advance, ice thickening, and locally increased velocities. However, the numerical approach of defining a kinematic wave response may not be comparable to field observations, where measureable changes in the field would be more apt to define the response. Other factors seem to explain differences in glacier response. For example, slope steepness explains variations in glacier behavior with small mass balance perturbations. On steeper slopes, the kinematic wave is diffused less because the glacier is inherently thinner. However, this seems to not hold true for more extreme mass balance perturbations, where slope steepness seems to not affect the glacier's response. However, more research into this relationship is necessary.

For the Nisqually Glacier experiments, the reestablishment time back to equilibrium is much quicker than for the theoretical model. This is largely explained by the greater kinematic wave velocities for the Nisqually Glacier model caused by its small ice thickness and steep slopes. The reproduction of the historical waves of the 1940s-1960s proved to be insightful. A 6 m. w.e. perturbation for 3 years was necessary to produce similar waves. However, this perturbation is unreasonable in the physical world and leads to the conclusion that some other factor, such as variations in basal sliding (Van de Waal and Oerlemans, 1995), are responsible 
for kinematic wave formation and propagation. Glacier advances for the Nisqually Glacier experiments showed that for even slight mass balance perturbations advance of the glacier is significant. A $50 \mathrm{~m}$ advance (caused by $0.5 \mathrm{~m}$. w.e. for 1 year) would be highly noticeable even in the field.

Future research is needed to determine the relationship between slope steepness and kinematic wave formation. Although the results suggest that steeper slopes show a more prominent glacier response due to small mass balance perturbations, glacier response due to larger mass balance perturbations remains unclear. In addition, more research is needed in order to accurately determine the formation of kinematic waves on the Nisqually Glacier. Future research will determine if other factors, such as basal sliding, contribute to the formation. Determining if the mass balance curve for the model affects kinematic wave response is important. Because the Nisqually Glacier's mass balance is relatively unknown, using different functions may highlight if the mass balance of a glacier is critical in pinpointing kinematic wave formation. This should include experiments with stable and retreating Nisqually Glaciers to determine if the formation is affected by the overall glacier condition. 


\section{References}

Bidlake, W.R., Josberger, E.G., and Savoca, M.E., 2005, Water, Ice, and Meteorological Measurements at South Cascade Glacier, Washington, Balance Year 2003: U.S. Department of the Interior, U.S. Geological Survey, Scientific Investigations Report 2005-5210

Bidlake, W.R., Josberger, E.G., and Savoca, M.E., 2007, Water, Ice, and Meteorological Measurements at South Cascade Glacier, Washington, Balance Year 2004 and 2005: U.S. Department of the Interior, U.S. Geological Survey, Scientific Investigations Report 2007-5055.

Bidlake, W.R., Josberger, E.G., and Savoca, M.E., 2010, Modeled and Measured Glacier Change and Related Glaciological, Hydrological, and Meteorological Conditions at South Cascade Glacier, Washington, Balance and Water Years 2006 and 2007: U.S. Department of the Interior, U.S. Geological Survey, Scientific Investigations Report 2010-5143.

Driedger C.L., and Kennard, P.M., Ice Volumes on Cascade Volcanoes: Mount Rainier, Mount Hood, Three Sisters, and Mount Shasta: U.S. Geological Survey Professional Paper 1365.

Greuell, W., Hintereisferner, Austria: mass-balance reconstruction and numerical modelling of the historical length variations: Journal of Glaciology, vol. 38, no. 129, pg. 233-244.

Heliker, C.C., Johnson, A.H., and Hodge, S.M., 1984, The Nisqually Glacier, Mount Rainier, Washington: A Summary of the Long-Term Observationsand a Comprehensive Bibliography: 1857-1979: USGS Open-file Report 83-541, US Geological Survey, Tacoma, WA

Hodge, S. M., 1972, The movement and basal sliding of the Nisqually Glacier, Mt. Rainier: Seattle, Wash., PhD dissertation, University of Washington, Department of Atmospheric Sciences.

Hooke, R.L., 2005, Principles of Glacier Mechanics: New York, Cambridge University Press, $429 \mathrm{p}$.

Krimmel, R.M., 2002, Glaciers of North America - Glaciers of the conterminous United States, Glaciers of the western United States: U.S. Geological Survey Professional Paper 1386-J2, p. J329-J381.

Lighthill, M.J., and Whitham, G.B., 1955, On Kinematic Waves: Proc. R. Soc. London, Ser. A, vol. 229 , no. 1178 pg. 281-345

Maohuan, H., 1990, On the temperature distribution of glaciers in China: Journal of Glaciology, vol. 36, no. 123, p. 210-216.

Meier, M.F., and Tangborn, W.V., 1965, Net budget and flow of South Cascade Glacier, Washington: Journal of Glaciology, vol. 5, pg. 547-566. 
Nye, J.F., 1960, The response of glacier and ice-sheets to seasonal and climatic changes: Proc. R. Soc. London, Ser. A, vol. 256, no. 1287, pg. 559-584.

Parizek, B.R., Alley, R.B., MacAyeal, D.R., 2005, The PSU/UofC finite element thermomechanical flowline model of ice-sheet evolution: Cold Regions Science and Technology, vol. 42, issue 2, pg. 145-168.

Parizek, B.R., 2000, Thermomechanical flowline model for studying the interactions between ice sheets and the global climate system, Master's thesis, The Pennsylvania State University.

Robinson, J. E., Sisson, T. W., and Swinney, D. D., 2010, Digital topographic map showing the extents of glacial ice and perennial snowfields at Mount Rainier, Washington, based on the LiDAR survey of September 2007 to October 2008, US Geological Survey Digital Data25 Series 549, United States Geological Survey, http://pubs.usgs.gov/ds/549/ (last access: Dec. 2015).

Skloven-Gill, J., and Fountain, A.G., 2015, Glacier change, kinematic waves, and outburst floods at Nisqually Glacier, Mountain Rainier, Washington, Data Analysis and Review, Department of Geology, Portland State University, Portland, Oregon.

Van de Waal, R.S.W., and Oerlemans, J., 1995, Response of valley glacier to climate change and kinematic waves: a study with a numerical ice-flow model: Journal of Glaciology, vol. 41, no. 137 , pg. 142-152.

Veatch, F.M., 1969, Analysis of a 24-photographic record of Nisqually glacier, Mount Rainier National Park, Washington: U.S. Geological Survey Professional Paper 631.

USGS, 2012, Volcano Hazards Program: Mount Rainier: Glaciers Help to Shape Mount Rainier: http://volcanoes.usgs.gov/volcanoes/mount_rainier/geo_hist_glaciers.html (last access: Dec. 2015) 